\title{
THORPEX RESEARCH AND THE SCIENCE OF PREDICTION
}

D. B. Parsons, M. Beland, D. Burridge, P. Bougeault, G. Brunet, J. Caughey, S. M. Cavallo, M. Charron, H. C. Davies, A. Diongue Niang, V. Ducroce, P. Gauthier, T. M. Hamill, P. A. Harr, S. C. Jones, R. H. Langland, S. J. Majumdar, B. N. Mills, M. Moncrieff, T. Nakazawa, T. Paccagnella, F. Rabier, J.-L. Redelsperger, C. Riedel, R. W. Saunders, M. A. Shapiro, R. Swinbank, I. Szunyogh, C. Thorncroft, A. J. Thorpe; X. Wang, D. Waliser, H. Wernli, and Z. Toth

THORPEX was a 10-yr international research program designed to accelerate the rate of improvement in the accuracy of predictions of high-impact weather.

$\mathrm{T}$ he Observing System Research and Predictability Experiment (THORPEX) was designed to accelerate the rate of improvement in the accuracy of predictions of high-impact weather from 1 day to 2 weeks for the benefit of society, the economy, and the environment (Shapiro and Thorpe 2004). This goal was largely motivated by the desire to reduce fatalities and human suffering from devastating weather events, which occur worldwide and include, for example, disasters such as 1) the Black Saturday bushfires in the state of Victoria, Australia, in $1999 ; 2$ ) the flood and debris flow tragedy brought about by torrential rains in state of Vargas, Venezuela, in 1999; 3) Hurricane Katrina in the Gulf Coast of the United States in 2005; 4) the great southern China ice storm of 2008; 5) Cyclone Nargis in Myanmar in 2008 ; 6) the tornado outbreaks in Joplin, Missouri, and across central Alabama in 2011; 7) Superstorm Sandy in the eastern United States in 2012; 8) the widespread flooding in Mozambique in 2000 and South Africa in 2010 and early 2011; 9) the central European floods of June 2013; and 10) Typhoon Hiyan in the Philippines and Southeast Asia in 2014. Weather events that are not classified as disasters and, as such, do not receive widespread media attention are also major sources of injuries and fatalities. For example, using statistics from 2002-12, the Federal
Highway Administration (2014) estimates that over 1.3 million weather-related traffic crashes occur annually in the United States, injuring more than 480,000 people and causing 6,250 fatalities.

THORPEX was also motivated by the rapidly growing economic impacts of weather events. For example, the United Nation's Global Assessment Report on Disaster Risk Reduction (United Nations 2013) estimates that the direct economic impact of disasters worldwide has exceeded $\$ 100$ billion per year over the past three years without the inclusion of uninsured losses. Significant economic impacts from weather also occur apart from major disasters as the influence of day-to-day weather variability on the U.S. economy was estimated to be approximately $3.4 \%$ of the gross domestic product (Lazo et al. 2011) or almost $\$ 600$ billion of annual weather sensitivity using the seasonally adjusted numbers for the first quarter of 2014. While the improved utilization of weather products will certainly increase economic efficiency and reduce casualties, accurate forecasts remain the critical and essential foundation for obtaining these desirable outcomes. One critical path forward is advancing the skill of medium-range (from 3 days to 10-15 days) forecasts from global numerical weather prediction (NWP) systems, as such forecasts provide early warnings of major hydrometeorological 
disasters. Advancements in global NWP will also foster improvements in forecast skill across a wide range of time scales. For example, global models typically provide the boundary conditions and, in some cases, the initial state for high-resolution regional simulations. Thus, advances in global forecast systems will likely lead to improved predictions on time scales as short as hours. The potential benefits of advancing global NWP also extend to weeks and even months as seasonal forecast models are based, in large part, on NWP systems. Thus, advancing medium-range prediction provides the potential for a wide variety of users of weather information to obtain a greater range of economic benefits from improved prediction.

In response to these challenges, THORPEX was established as a 10 -yr program of the World Weather Research Program (WWRP) of the World Meteorological Organization (WMO) under the Commission for the Atmospheric Sciences (CAS). THORPEX established a framework for international cooperation involving networks of researchers from operational centers, research institutes, and the academic community as well as the users of forecast information. THORPEX was the first extensive international research effort focused on advancing the prediction of high-impact weather across the time scale from one day to two weeks since the Global Atmospheric Research Program (GARP), which began in 1967 and concluded with the Alpine Experiment (ALPEX) field campaign in 1982.

affiliations: Parsons, Cavallo, Riedel, and Wang-School of Meteorology, University of Oklahoma, Norman, Oklahoma; BelAND-Environment and Climate Change Canada, Dorval, Quebec, Canada; Burridge, Caughey, and NakazaWa-World Weather Research Program, World Meteorological Organization, Geneva, Switzerland; BOUgeAULT AND DUCROCQ-Météo-France/CNRS, CNRM/GAME, Toulouse, France; Brunet, SAUnders, AND SWINBANKMet Office, Exeter, United Kingdom; CHARRON-Meteorological Research Division, Environment and Climate Change Canada, Dorval, Quebec, Canada; DAVIES AND WERNLI-Institute for Atmospheric and Climate Science, ETH Zurich, Zurich, Switzerland; DıONGUE NIANGPhysical Sciences Division, Agence nationale de l'aviation civile et de la météorologie, Dakar-Yoff, Senegal; GAUTHIER-Département des sciences de la Terre et de l'atmosphère, Université du Québec à Montréal, Montreal, Quebec, Canada; HaMILL AND TotH—NOAA/ Earth System Research Laboratory, Boulder, Colorado; HARRDepartment of Meteorology, Naval Postgraduate School, Monterey, California; JONES—Deutsche Wetterdienst, Offenbach, Germany; LANGLAND-Marine Meteorology Division, Naval Research Laboratory, Monterey, California; MajumDar-Rosenstiel School of Marine and Atmospheric Science, University of Miami, Miami, Florida; MılısFaculty of Environment, University of Waterloo, Waterloo, Ontario,
HISTORY OF THE PROGRAM. The earliest THORPEX planning was focused on the concept that predictive skill could be improved through employing additional measurements, such as aircraft-deployed dropsondes, in regions where forecast simulations were particularly sensitive to errors in the initial state. This adaptive approach was first demonstrated utilizing the datasets collected during the Fronts and Atlantic Storm Track Experiment (FASTEX) project in 1997 (Joly et al. 1997, 1999), the 1999 and 2000 Winter Storm Reconnaissance programs (Szunyogh et al. 2000, 2002), and the North Pacific Experiment (Langland et al. 1999). In an editorial accompanying the Quarterly Journal of the Royal Meteorological Society special issue on FASTEX (1999, Vol. 125, No. 561; Thorpe 1999), Dr. Alan Thorpe called for the continuation of research to improve the prediction of damaging extratropical cyclones and for the extension of FASTEX adaptive measurement techniques to the Pacific storm track. Subsequently, Dr. Rolf Langland was the lead author of an early vision document for the program in the United States, again urging data impacts studies over the Pacific, which would address North American forecast needs (R. Langland and M. Shapiro 1999, unpublished manuscript). Community input from an international workshop in 2000, the formation of the International Core Steering Committee (ICSC) in early 2002, an international planning workshop in March 2002, and a U.S. Tiger Team meeting and a National Oceanic and Atmospheric Administration (NOAA) planning meeting later

and Environment and Climate Change Canada, Dorval, Quebec, Canada; MONCRIEFF-National Center for Atmospheric Research, Boulder, Colorado; PACCAGnelLa AND ThORPE-Servizio Idro-Meteo-Clima, ARPA Emilia-Romagna, Bologna, Italy; RABIER-European Centre for Medium-Range Weather Forecasts, Reading, United Kingdom; RedelsPerger-Laboratoire de Physique des Oceans, Brest, France; SHAPIRO-NOAA/Earth System Research Laboratory, and National Center for Atmospheric Research, Boulder, Colorado; SzUNYOGHTexas A\&M University, College Station, Texas; THORNCROFTDepartment of Atmospheric and Environmental Science, University at Albany, State University of New York, Albany, New York; WALISERNASA Jet Propulsion Laboratory, Pasadena, California CORRESPONDING AUTHOR E-MAIL: David B. Parsons, dparsons@ou.edu

The abstract for this article can be found in this issue, following the table of contents.

DOI:I0.II75/BAMS-D-14-00025.I

A supplement to this article is available online (I0.II75/BAMS-D-I4-00025.2)

In final form 26 May 2016

(C)2017 American Meteorological Society 
that same year broadened THORPEX into a major atmospheric research program with goals that extended well beyond the early focus on adaptive measurements.

Drs. Melvyn Shapiro and Alan Thorpe served as the visionary lead authors for the International Science Plan, seeking input from numerous contributing authors and others in the research and operational communities (Shapiro and Thorpe 2004). The Science Plan was completed in 2002 and THORPEX was officially recognized with the establishment of the THORPEX ICSC by the CAS in 2002, with the first meeting of the ICSC in Oslo, Norway, on 15-16 October 2002 (Fig. 1, top; see sidebar "Naming of the program" for a discussion of the THORPEX name). Subsequently in 2003, the 14th Congress of the WMO established "THORPEX: A Global Atmospheric Research Program" as a 10-yr-long international research and development program with the goal of accelerating improvements in the forecasting of highimpact weather events. To
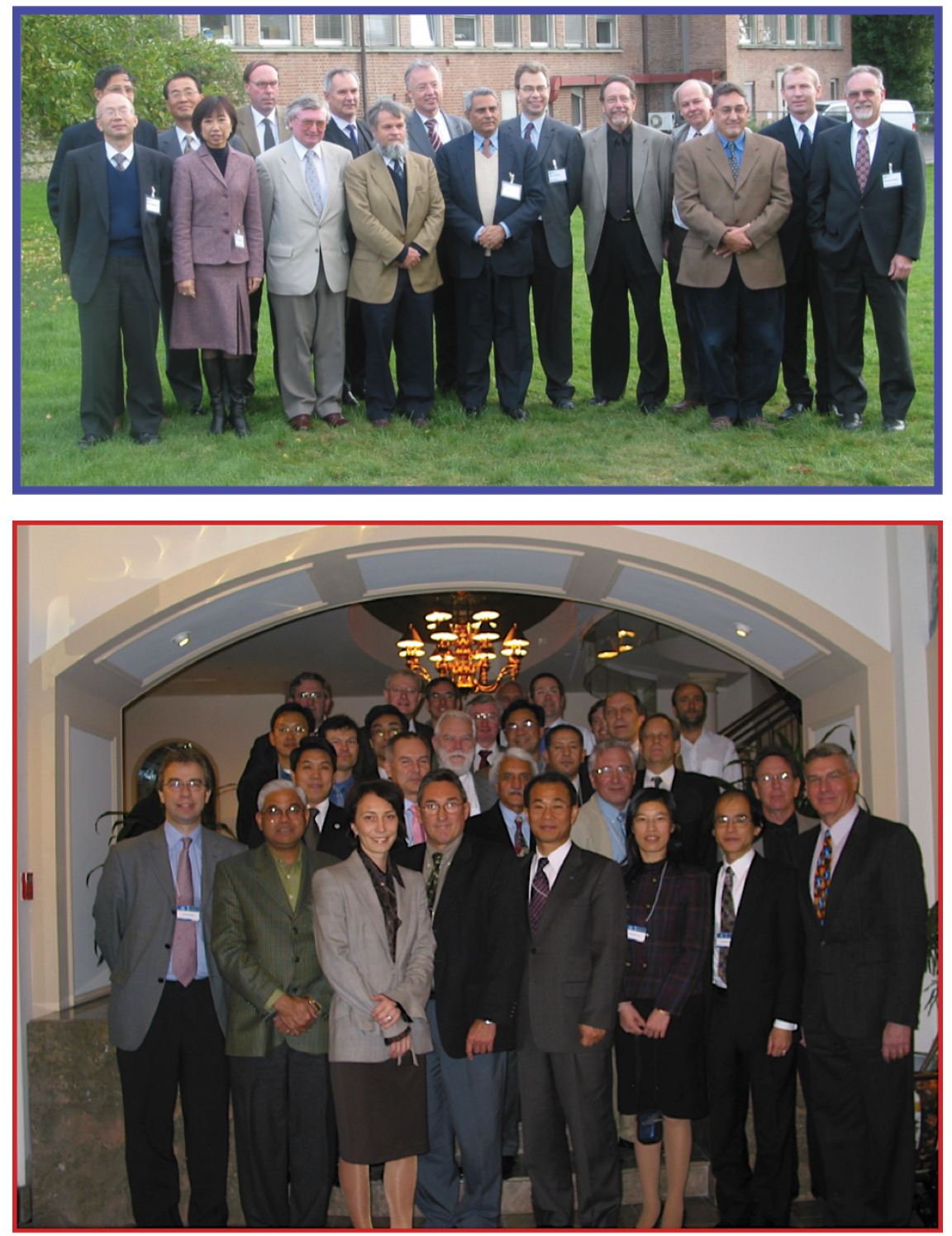

FIG. I. (top) The first meeting of the ICSC for the WWRP/THORPEX program in Oslo, Norway, on 15-16 Oct 2002. (bottom) The first full meeting of the THORPEX ICSC and the chairs and co-chairs of the Science Advisory Board, the working groups, and the regional committees was held in Montreal, Canada, on 16-17 Dec 2003.

establish a framework for

implementing these broad scientific goals, Dr. David Rogers led a writing team that developed the implementation plan (Rogers et al. 2005). This plan set milestones and time lines for specific activities, while also adding to the scientific vision. To provide the funding for the coordination activities of THORPEX within the WMO, such as the drafting of the implementation plan and other meetings, workshops, and symposia, the THORPEX Trust Fund was also established in 2003. The donor nations included Canada, China, France, Germany, Japan, Norway, South Korea, the United Kingdom, and the United States. Within these

nations, the donations for the trust fund were typically generated through the national meteorological and hydrometeorological services. Representatives of these donor nations, along with representatives from Australia, Brazil, India, Morocco, Russia, and South Africa, comprised the ICSC. The implementation plan was approved in 2003, leading to THORPEX formally commencing on 1 January 2005 with the founding of the THORPEX International Project Office within the WWRP. Dr. David Burridge was the founding Director of the Project Office, a position that he continued to hold through 2011. Dr. Jim Caughey worked 
in the Project Office during the entire duration of the program.

\section{SCIENTIFIC FOCI AND THE ORGANIZA- TION OF THE PROGRAM. The Science Plan and} the presentations to the CAS and WMO Congress by Shapiro and Thorpe provide insight into the vision of an ambitious global research program that identified a wide range of research activities likely to advance predictive skill on the time scale from one day to two weeks (Shapiro and Thorpe 2004). The selection of specific research activities were driven by 1) significant failures in the forecasts of high-impact weather; 2 ) the inability to extend the range of useful prediction skill out to the two weeks; 3 ) a poor description of tropical influences on extratropical forecasts; and 4) inadequate skill in predicting mesoscale weather, such as precipitation. The vision also described parallels between GARP and THORPEX, not the least because the early vision of THORPEX was that it might have a global campaign similar to the First GARP Global Experiment (FGGE). THORPEX also focused on many of the same problems as GARP, such as tropical convection, the West African monsoon, and polar prediction, but it also included distinctive differences, as THORPEX urged that significant energy be devoted to data assimilation and ensemble prediction.

The THORPEX Science Plan proposed four subprograms focused on 1) predictability and dynamical processes (PDP), including the linkage between Rossby wave dynamics and high-impact weather; 2) global observing system design and demonstration, including the targeting of additional observations to improve forecast skill; 3) data assimilation and observing strategies, including a better representation of flow-dependent background error covariances in the assimilation process; and 4) societal and economic applications of improved forecasts, including the improved utilization of ensemble predictions. The initial plan did not include an emphasis on model physics, as the intent was for this component to be handled by the CAS-World Climate Research Programme (WCRP) Working Group on Numerical Experimentation (WGNE). As a program of the WWRP, THORPEX followed the strategy of organizing these subprograms into working groups, with members undertaking collaborative research and playing major roles in the design, implementation, and execution of specific research projects. Thus, their activities went well beyond the frequently utilized WMO strategy of committees built around organizing meetings, coordination, and reporting. The inclusion of a socioeconomic subprogram was consistent with the long-held strategy of the WWRP to include a societal component in all its projects. Given that this WWRP strategy was conceived over 20 years ago and that today we have a growing focus on incorporating social science into the weather enterprise, we must acknowledge Rit Carbone (early Chair of the WWRP Science Steering Committee), Keith Browning, and other members of the WWRP for their insightful vision.

The subsequent implementation plan (Rogers et al. 2005) called for a technical advisory board, a stakeholder's panel, self-funded and self-organized regional committees, a science advisory board, and two additional working groups (Fig. 2, top). The science advisory board was responsible for the scientific evaluation and review of the program and was initially chaired by Shapiro and Thorpe. Regional committees were established in Asia, North America, Europe, Africa, and the Southern Hemisphere to promote and organize regional contributions to the international program and to develop specific activities (e.g., field campaigns, demonstration projects, modeling experiments) focused on regional needs. These regional committees were established 
since high-impact weather events vary strongly with location, as some nations are primarily concerned with tropical cyclones while others are concerned with extratropical storms, flooding, severe convection, or some combination of these events. The first joint meeting of the THORPEX ICSC and the leads for the science advisory board, the working groups, and the regional committees was held in Montreal on 16-17 December 2003 (Fig. 1, bottom). As the program developed, the organizational structure was substantially streamlined (Fig. 2, bottom).

\section{THORPEX SCIENCE: FROM THE POLES TO} THE TROPICS. This section describes THORPEX's role in addressing three critical research areas at the intersection of large-scale dynamics and global numerical weather prediction.

Research aimed at advancing prediction of polar processes. The vision for polar research developed during the drafting of the THORPEX implementation plan (Rogers et al. 2005). The need to advance predictive skill for polar weather and related environmental parameters (e.g., sea ice and blowing snow) is driven by the amplification of climate change at polar latitudes combined with increasing socioeconomical interest. Large analysis uncertainties and prediction errors were shown to exist during the last two

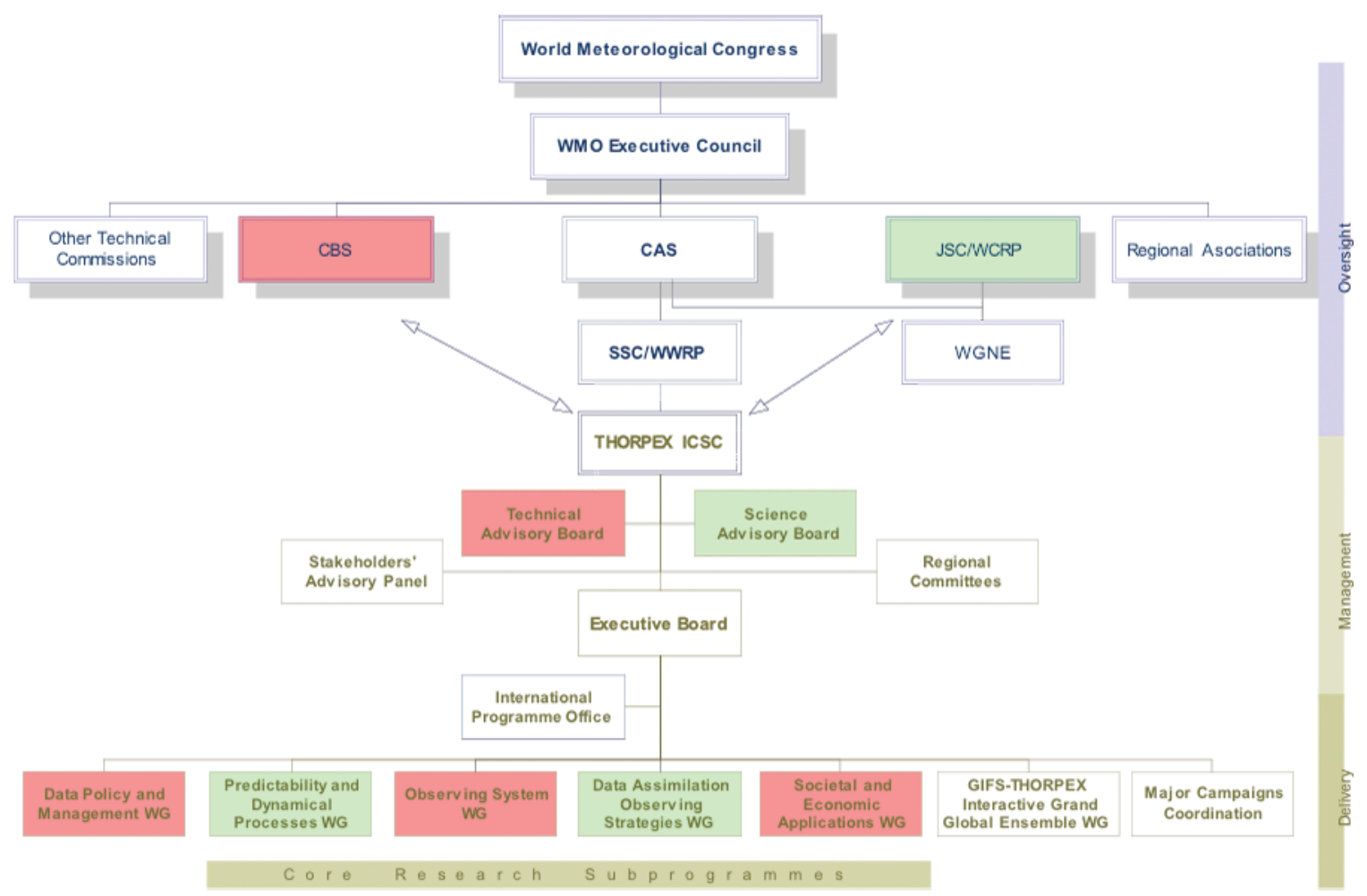

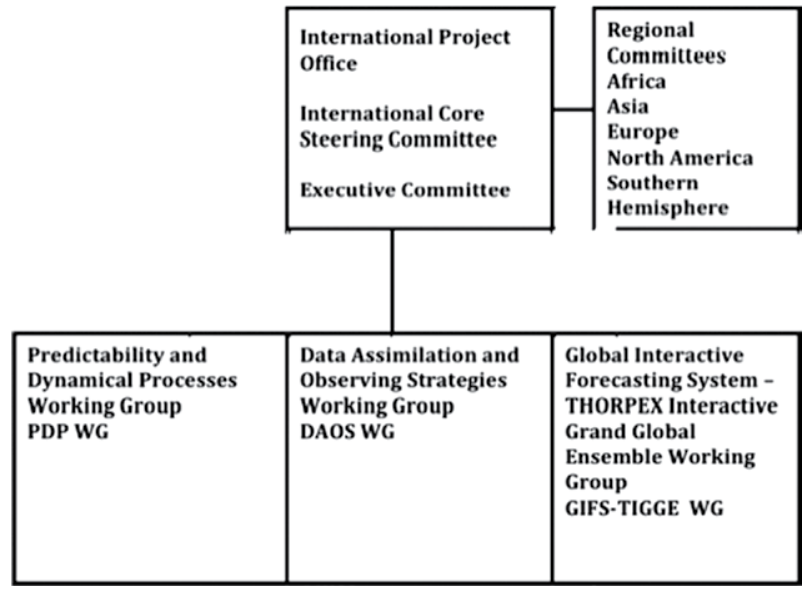

FIG. 2. (top) The ambitious THORPEX organizational chart as proposed in the THORPEX implementation plan (Rogers et al. 2005). The plan called for six working groups (WGs) and three advisory groups. Note that some abbreviations are not denoted in the article: WMO Commission for Basic Services (CBS), Joint Science Committee of the WCRP (JSC/ WCRP), and Science Steering Committee of the WWRP (SSSC/WWRP). (bottom) A simplified organizational chart for THORPEX revealing three working groups, regional committees, and the management structure (International Project Office, ICSC, and the Executive Committee). 
to three decades north of the Arctic Circle by Jung and Leutbecher (2007). Improvements in weather, seasonal, and climate forecasts over polar locations have been delayed because of the extreme conditions and a general greater focus on advancing model skill for more densely populated midlatitude and tropical regions.

The THORPEX polar activities included a cluster of projects associated with the International Polar Year (IPY) 2007-08 (Nordeng et al. 2007). The concept of grouping various projects into a THORPEX cluster was encouraged by the IPY organization so that the cluster included projects whose intellectual motivation and funding stream were directly tied to THORPEX, with independent projects whose goals simply overlapped with the THORPEX motivation. Most projects within the THORPEX IPY cluster focused on the Arctic (see sidebar "The THORPEX IPY cluster of projects within the Arctic"). The lone Antarctic project within this cluster was Concordiasi, a joint French-U.S. effort organized as a THORPEX project that took place during the austral springs from 2008 to 2010, with an intensive observing period in austral spring 2009 (e.g., Rabier et al. 2010, 2013). Concordiasi was a unique multidisciplinary project with measurement strategies that included surface observations and longduration, zero-pressure balloons that drifted in the stratosphere carrying instrumented gondolas. This instrumentation varied and included small lightweight sensors to measure ozone, particle counters to examine the microphysics of stratospheric clouds,
GPS radio occultation systems, and a driftsonde gondola that deployed dropsondes on demand. The driftsonde system was carried on 13 gondolas and produced 644 high-quality soundings over a continent generally lacking in in situ measurements. The ballooning for Concordiasi was supported by the French Space Agency (Centre National d'Études Spatiales) and guided by an operational targeting system at Météo-France. Ironically, the driftsonde system, which was a central component of Concordiasi, was developed by the National Center for Atmospheric Research (NCAR; Cohn et al. 2013) in response to the early THORPEX vision of field campaigns over the Pacific.

Concordiasi resulted in a diverse range of research findings that included 1) the first quasi-Lagrangian observations of Antarctic spring ozone providing new insight into the temporal and spatial patterns of ozone loss and an opportunity to evaluate the ability to represent these losses in chemical models; 2) in situ particle and temperature observations leading to the estimation of the nucleation rate of nitric acid trihydrate associated with the formation of polar stratospheric clouds; 3 ) evidence of irreversible filamentation of potential vorticity (PV) within the polar vortex likely associated with Rossby wave breaking; 4) observation of the momentum flux associated with gravity waves and tests of the ability to accurately parameterize these processes in numerical models; 5) evaluation of satellite remote sensing, including comparisons of temperature profiles from satellite retrievals, dropsondes, and radiosondes that

\section{THE THORPEX IPY CLUSTER OF PROIECTS WITHIN THE ARCTIC}

- The THORPEX Arctic Weather and Environmental Prediction Initiative (TAWEPI) investigated various aspects of Arctic weather systems: snow processes, polar clouds, sea ice, and the ozone layer. Chung et al. (2010, 20II) describe efforts to couple atmosphere, sea ice, ocean currents, and snow models over the Arctic basin. The main objective of the research was to develop and validate a regional weather prediction model (e.g., Deacu et al. 2010) and the use of satellite observations (Garand et al. 20II) to enhance Environment Canada's ability to forecast weather and environmental conditions in the Arctic.
- The Norwegian IPY-THORPEX focused on the optimal utilization of new satellite data, targeted observations, modeling of the latent heat cycle, extreme weather, and advancing operational NWP ensembles (Kristjánsson et al. 20II). Research from the project improved knowledge of high-latitude clouds, cloud-radiation interaction, and other key energy exchanges. Process studies and targeted observation experiments were also performed on polar lows.

- The Greenland Flow Distortion Experiment (GFDex) focused on Greenland tip jets, air-sea interactions, barrier winds, and polar lows. These circulations influence weather systems that impact the North Atlantic and Europe and also play critical roles in the climate system through influencing the overturning of the thermohaline circulation. The field campaign took place in February 2007 (Renfrew et al. 2008), and the research results were presented in a compendium of 10 papers in a special issue of the Quarterly Journal of the Royal Meteorological Society (2009, Vol. 135, No. 645).

- The Storm Studies of the Arctic (STAR) included enhanced observations in the eastern Canadian Arctic, gap flow, air-sea interactions, orographic precipitation, and the interaction of cyclones with topography (Hanesiak et al. 20I0). 
revealed a cold bias generally present in all satellite retrievals; and 6) proof of concept of the ability to obtain refractivity and derived temperature soundings from balloon-borne GPS radio occultation systems, which produced an impressive 711 vertical profiles of temperature from only two balloon flights. For more information, the reader is referred to Rabier et al. (2013), Cohn et al. (2013), and the electronic supplement (http://dx.doi.org/I0.II75/BAMS -D-14-00025.2). ${ }^{1}$

The Concordiasi observations also provide a unique opportunity to assess and improve mesoscale models with their potential to better represent local circulations, such as katabatic flows and extreme wind events, which are relevant to a variety of topics ranging from the safe air transport of scientific personnel to the water budget of the continent. Regional modeling in this environment, however, is challenging as in situ observations are sparse over the continent and surrounding oceans and the viewing angles complicate and limit the use of geostationary satellite observations. The challenge of initializing regional modeling over Antarctica is illustrated in Fig. 3, where time series of estimates of forecast errors for potential temperature at the tropopause is shown for NOAA's Global Forecast System (GFS) and two different data assimilation methods applied to the Antarctic Mesoscale Prediction System (AMPS). This model is a real-time, high-resolution regional modeling system run over Antarctica and maintained by NCAR (e.g., Powers et al. 2012). AMPS, utilizing a three-dimensional data assimilation strategy heavily influenced by the GFS, can slightly reduce uncertainties in initial conditions relative to the GFS. However, since the AMPS forecast is not initialized with the same model that created the basis for their analysis, an adjustment (called model spinup) occurs in a short-term forecast arising from differences in processes represented in one model's analysis of an atmospheric state versus those that a different forecast model can represent (e.g., Rodwell and Palmer 2007; Klocke and Rodwell 2014). Thus, even though AMPS slightly improves the initial conditions, downscaled forecasts from the AMPS appear to have a model spinup problem that degrades short-term forecasts with rapid error growth that well exceeds that of the GFS during the first $\sim 36 \mathrm{~h}$ of the simulation. The problem of model spinup in downscaled forecasts can be alleviated if data assimilation is performed using

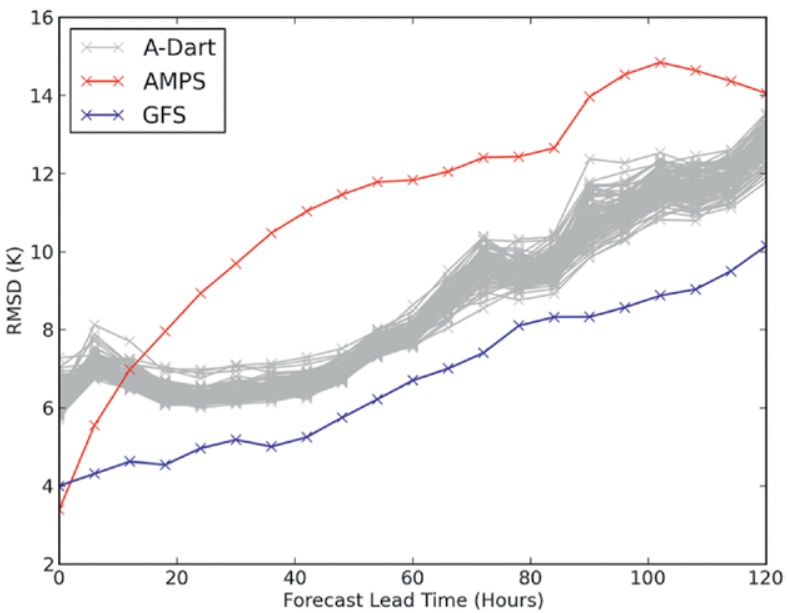

FIG. 3. Tropopause potential temperature root-meansquare difference (RMSD) with respect to ECMWF interim reanalysis (ERA-Interim; Dee et al. 20II) of forecasts beginning on 28 Sep 2010 for AMPS (red), GFS (blue), and the A-DART ensemble (gray). Each 6-h synoptic time is shown by the $x$ symbols.

the same model as used to perform forecast simulations (e.g., Rodwell and Palmer 2007; Cavallo et al. 2016). This reduction in the spinup is illustrated by utilizing a version of the AMPS model, in combination with the Data Assimilation Research Testbed (DART; Anderson et al. 2009) that was developed as part of the Concordiasi project over the Antarctic and was tested during September-October 2010. This particular modeling configuration, referred to as A-DART, is an ensemble-based, high-resolution regional modeling system using an ensemble-adjustment Kalman filter. This approach offers a special appeal in the data-sparse Antarctic, as the impact per observation may be greater in this data assimilation approach. The A-DART simulations begin with a greater initial condition error than the other two models, but with a short spinup of about $6 \mathrm{~h}$, so that each ensemble member forecast in A-DART exhibits a lower bias than AMPS forecasts after $12 \mathrm{~h}$ (Fig. 3). The A-DART simulations in Fig. 3 utilize only a small fraction of the available dataset, and current efforts are focusing on reducing the initial condition error for this approach.

Studies of predictability and dynamical processes in the midlatitudes. The THORPEX planning process (Shapiro and Thorpe 2004) revealed that series of devastating weather events can be triggered at the leading

\footnotetext{
${ }^{1}$ The large number of publications associated with the 10-yr THORPEX project has resulted in the necessary strategy of discussing results in general terms in this paper and referring the reader to listings of relevant THORPEX and THORPEX-related publications in an electronic supplement.
} 
edge of propagating Rossby wave trains (Fig. 4). Subsequent research has advanced knowledge of the interplay between Rossby wave dynamics and highimpact weather. Specific studies include delineating the waveguides structure in terms of the isentropic PV gradient across the extratropical and/or subtropical jet stream and developing refinements and alternatives to the traditional Hovmöller diagram for detecting propagation along the waveguide. Research determined that the source of major perturbations of the waveguides could be traced to tropopause polar vortices that originate poleward of the jet with large amplitude within the lowermost stratosphere and to diabatically modified features originating equatorward of the jet within in the uppermost troposphere. More accurate representations of these two types of well-defined flow features "upstream" of their interaction with the waveguide could lead to improved forecasts of high-impact weather events downstream.

However, the waveguide can also be disrupted by diabatically modified outflows in the upper levels, as, for instance, the extratropical transition of a tropical cyclone can lead, somewhat disconcertedly, to strong

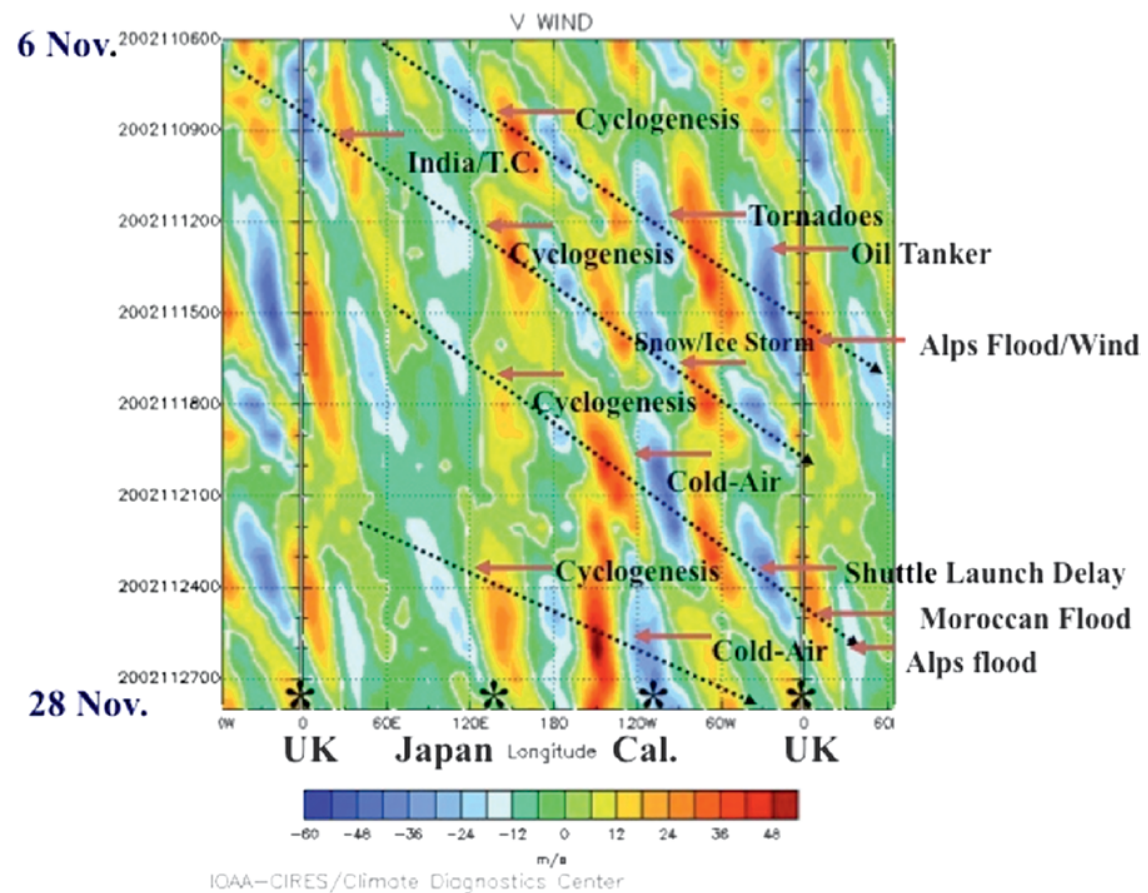

Fig. 4. One of the provocative challenges provided by Dr. Melvyn Shapiro for the predictability and dynamical processes portion of THORPEX showing the clear linkages between high-impact weather and Rossby wave trains. This figure was shown in the early THORPEX planning documents and depicts a Hovmöller diagram of the meridional winds at $250 \mathrm{hPa}\left(\mathrm{m} \mathrm{s}^{-1}\right)$ averaged over the $35^{\circ}-60^{\circ} \mathrm{N}$ latitude band. The time period is from 6 to 28 Nov 2002 and the dashed lines indicate the propagation of the Rossby wave trains. increases in the forecast uncertainty downstream. This process is illustrated in Fig. 5, where the spread of the forecast ensemble is evident downstream in space and time from when the tropical cyclone enters the westerlies (Harr et al. 2008). THORPEX also advanced understanding of the nature and cause of forecast errors. For example, Davies and Didone (2013) showed that PV-based metrics provide a sensitive measure of prediction performance and also illustrate paths toward further improvement. In addition, various illuminating approaches have been developed for assessing the quality of forecasts, understanding forecast busts, and diagnosing the nature and cause of forecast error for midlatitude events and tropical cyclones. Many of these PDP studies illustrate THORPEX's hallmark strategy of blending theoretically orientated research with operational prediction activities to advance scientific knowledge relevant to NWP.

Organized research efforts were carried out by the THORPEX PDP Working Group and through national contributions, such as the Predictability and Dynamics of Weather Systems in the AtlanticEuropean Sector (PANDOWAE; e.g., Lang et al. 2012; Boettcher and Wernli 2013) project funded by the German Research Foundation (DFG) and the Diabatic Influences on Mesoscale Structures in Extratropical Storms (DIAMET; e.g., Martínez-Alvarado et al. 2014; Vaughan et al. 2015) project supported by the United Kingdom's National Environmental Research Council. PANDOWAE concentrated on 1) the generation, propagation, and breaking of upperlevel Rossby wave trains; 2) moist processes and diabatic Rossby waves; and 3) ensembles and adaptivity. The phenomena of interest to PANDOWAE were European windstorms, Mediterranean cyclones, tropical cyclones and their transformation into extratropical systems, and severe convection over Europe. The main aims of 

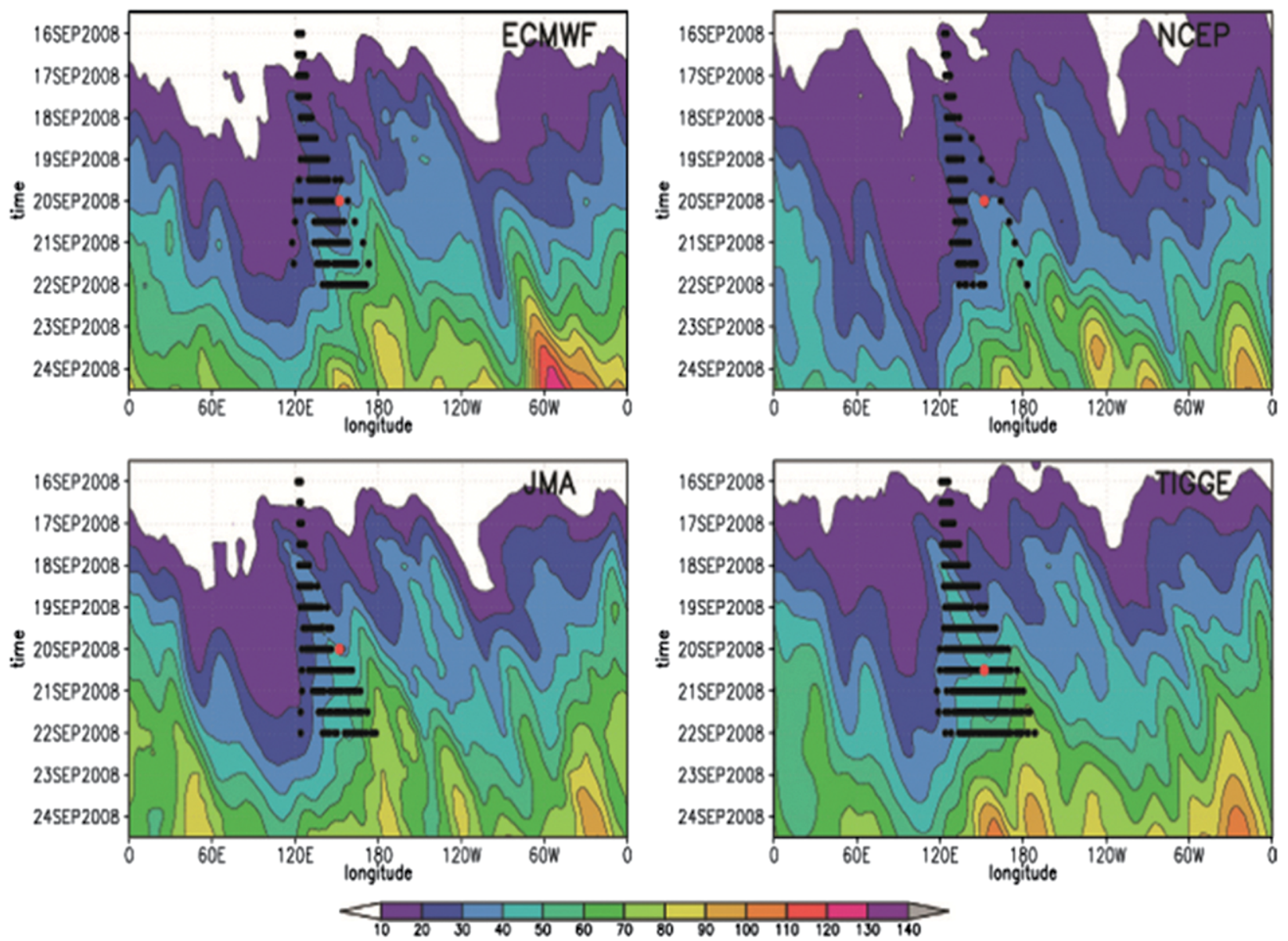

FIG. 5. The 500-hPa-height standard deviation (m) among ensemble forecasts initiated at I200 UTC I5 Sep 2008 from the (top left) ECMWF, (top right) NCEP, and (bottom left) JMA operational ensemble prediction systems, and (bottom right) all systems contained in the TIGGE database. The standard deviation is averaged between $40^{\circ}$ and $60^{\circ} \mathrm{N}$. The black dots define the forecast positions of Typhoon Sinlaku in all ensemble members. The red dot defines the location of Typhoon Sinlaku at the time of extratropical transition.

DIAMET were to 1) investigate real mesoscale structures during aircraft field experiments, 2) examine observed physical processes and their representation in forecast models, and 3) address the problem of predictability using a combination of ensemble and data assimilation techniques. These two projects alone resulted in more than 70 journal articles published in the refereed literature and more than 30 theses and dissertations illustrating the success of national strategies that act upon and aggressively fund organized, national efforts in response to research priorities identified by an international program.

PANDOWAE and DIAMET represent strong national contributions to THORPEX built around the academic community undertaking PDP research on midlatitude systems. In contrast, no similar project, apart from field campaigns such as Concordiasi and the THORPEX Pacific Regional Campaign (T-PARC), was funded within the United States so that individuals or small teams of investigators from the academic community carried out much of the PDP research. Thus, directly crediting PDP research to THORPEX within the United States is difficult. However, in the first few years of THORPEX, program managers at the National Science Foundation (NSF) did keep track of funded proposals related to PDP that either used THORPEX as a motivation for their work or claimed that their results would contribute to THORPEX goals. This "count" suggested that THORPEX did indeed impact the direction of fundamental PDP research within the academic community, but not likely to the same extent as the targeted funded efforts such as DIAMET and PANDOWAE projects. ${ }^{2}$ These projects had special collections in the journals of

\footnotetext{
${ }^{2}$ Further details at www.pandowae.de and www.ncas.ac.uk /index.php/en/diamet-project-summary.
} 
the American Meteorological Society (AMS). An excellent review of THORPEX research in the PDP area can be found in Gray and Wernli (2015).

Year of Tropical Convection. The Year of Tropical Convection (YOTC) sought to advance knowledge of processes controlling the organization of tropical convection and its multiscale interaction with the goal of improving the treatment of these processes in numerical models. Further details are available in Waliser and Moncrieff (2008), Waliser et al. (2012), and Moncrieff et al. (2012), with a timeline of major YOTC activities in Fig. 6. The NSF, NOAA, National Aeronautics and Space Administration (NASA), and Office of Naval Research (ONR) provided interagency support to maintain the YOTC Project Office (http://yotc.ucar.edu). YOTC brought the weather (WWRP THORPEX) and climate (WCRP) research communities together to design and implement a program of mutual interest. At the time of the founding of THORPEX over 10 years ago, the concept of a large, formal effort at the intersection of weather and climate was often viewed with considerable skepticism. For example, during the earliest THORPEX planning, the idea that collaboration between weather and climate researchers could be an efficient path toward accelerating research progress for both communities often led to long philosophical discussions between the THORPEX leads and the program managers at NSF. These same THORPEX investigators were pleased to recently learn that the current plan at NSF is to have a program manager dedicated to overseeing a wide variety of research topics at the intersection of weather and climate.
YOTC's contributions to research at the intersection of weather and climate are largely based on the establishment of a "virtual global field campaign" (May 2008-April 2010) that includes global analyses, forecasts, and physical tendencies from the European Centre for Medium-Range Weather Forecasts (ECMWF) Integrated Forecast System (IFS) on a $25-\mathrm{km}$ computational grid. The inclusion of the tendencies in the archive provides a unique opportunity for the community to evaluate and improve the treatment of the physical and dynamical processes in a global model to an extent that was not been possible prior to YOTC. The archive also provided the information required to initialize high-resolution simulations or targeted modeling activities. YOTC also provides greatly improved access to data from multiple spaceborne sensors through the YOTCNASA Giovanni satellite data dissemination system, including a web-based application developed by the NASA Goddard Earth Science Data and Information Service Center (http://giovanni.gsfc.nasa.gov/).

YOTC attracted researchers utilizing high-resolution global weather prediction models, cloud-systemresolving models, theoretical studies, and enhanced access to a variety of routine observations. YOTC results include an assessment of the skill of mediumrange forecasts, a determination of the impact of improved initial conditions on forecasts of tropical cyclone tracks, and multimodel comparison of the skill of forecasting the boreal summer interseasonal oscillation. YOTC datasets have also facilitated fundamental tropical research, such as establishing precursors for tropical cyclone genesis on synoptic to intraseasonal

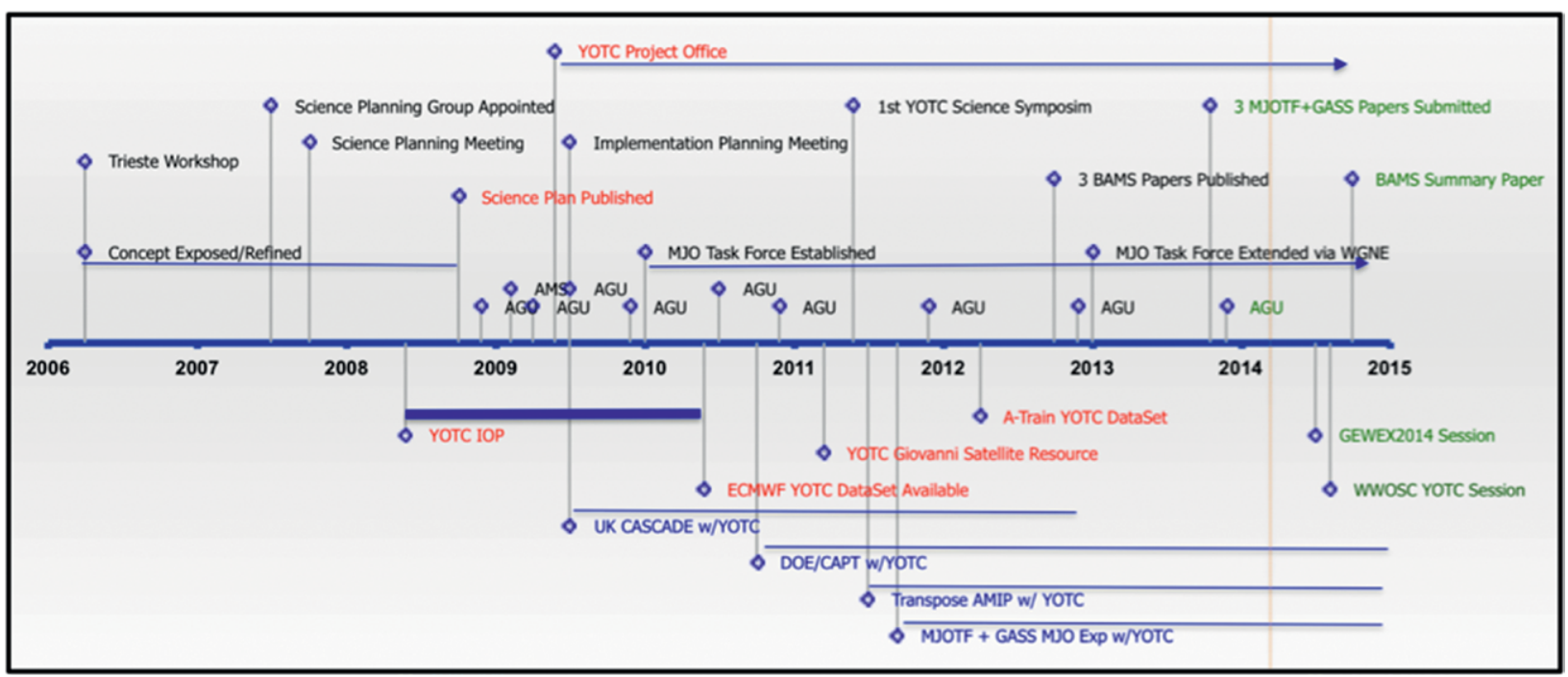

FIG. 6. Timeline of the WCRP/WWRP-THORPEX YOTC project depicting major events in the history of the project. 
time scales, investigations of the predictability of the Indian monsoon, and determination of the controls on tropical low-level cloud cover. YOTC was also the catalyst for international collaboration for research on the MaddenJulian oscillation (MJO; see sidebar "YOTC and international collaboration on the MJO").

The YOTC dataset has also proven valuable to mid- and high-latitude studies. For example, the WGNE/Working Group on Coupled Modeling (WGCM) TransposeAtmospheric Model Intercomparison Project (AMIP) II project, a contribution toward the Coupled Model Intercomparison Project phase 5 (CMIP5), selected the YOTC period to be the focus of experiments utilizing hindcasts and climate simulations, including a focus on cloud and related biases in the Southern Ocean and the Arctic. Closely related work from the U.S. Department of Energy (DOE) Cloud-Associated Parameterization Testbed systematically examined the correspondence between hindcasts and climate simulations with NCAR's Community Atmospheric Model versions 4 (CAM4) and 5 (CAM5) during YOTC.

RESEARCH ON NWP SYSTEMS. Adaptive observing strategies. A core objective of THORPEX was the development and demonstration of an interactive forecast system utilizing dynamical information from the forecast model to determine when and where to deploy observations in order to improve the prediction of specific high-impact events. Several field campaigns of THORPEX and the broader WWRP [e.g., African Monsoon Multidisciplinary Analysis (AMMA), Atlantic THORPEX Regional Campaign (A-TREC), Concordiasi, Convective and Orographically Induced Precipitation Study (COPS), Greenland Flow Distortion Experiment, Hydrological Cycle in the Mediterranean Experiment (HyMeX), Mediterranean Experiment (MEDEX), and T-PARC] included efforts to evaluate the impacts of additional observations on forecast skill. These field campaigns included making targeted measurements, often from dropsondes, in sensitive areas determined using methodologies, such as singular vectors and the ensemble transform Kalman filter (e.g., Wu et al. 2009). THORPEX also helped to establish the Eurorisk Preview data targeting system at the ECMWF that had the goal of improving forecasts of winter weather, tropical cyclones, and heavy precipitation events A THORPEX report (Majumdar et al. 2011) on the outcome of these research efforts was initiated by the THORPEX Data Assimilation Observing System (DAOS) Working Group. According to this report, the main outcomes from a decade of observation system experiments (OSEs) and forecast sensitivity studies were that 1) observations taken in sensitive areas had more value than those deployed randomly; 2 ) the value of adaptive observations depended on the modeling and assimilation systems; 3 ) the value of extratropical targeted data were positive, but small, on average; 4) adaptive observations sampled around tropical cyclones improved track forecasts; and 5) adaptive processing and selection of satellite data, particularly on larger spatial and temporal scales than achievable by targeting aircraft, can be a cost-effective approach. 
Thus, while the development and demonstration of an interactive forecasting system was one of the core objectives of THORPEX, this report argues that in situ targeting by aircraft is generally not justified for synoptic-scale predictions of midlatitude weather due to the small improvements in forecasts. This finding is consistent with another DAOS Working Group initiated study that evaluated the impact of targeted observations taken during NOAA's 2011 Winter Storm Reconnaissance program (Hamill et al. 2013), which revealed a neutral impact of these additional observations. The trend in the findings from the earliest targeting studies to more recent THORPEX research suggests that the average marginal impact of an individual observing system is decreasing. These results are further explored in Majumdar (2016). The trend in data impacts on forecast skill suggests that an ongoing assessment of the cost effectiveness of targeted and even routine observations is necessary.

The global observing system and predictive skill. THORPEX also contributed to assessing the cost effectiveness of the components of the global observing systems. The efforts of the DAOS Working Group and their collaborators are described in Rabier et al.'s (2008) review of THORPEX data assimilation research and in the results from THORPEX's Observation Impact Experiment (Gelaro et al. 2010). This research generally utilized either variational techniques to estimate observation impacts on the skill of global NWP forecasts (e.g., Langland and Baker 2004) or the degrees of freedom on the signal (DFS) approach to estimate the data impact on the analysis (e.g., Cardinali et al. 2004; Chapnik et al. 2006). These studies defined the relative contribution to analysis and forecast quality from a wide variety of observing systems (e.g., satellite-based remote sensing, surface and buoy observations, GPS radio occultation, upper-air observations from rawinsondes and aircraft, scatterometer-based observations, and derived atmospheric motion vectors). Research across different operational centers allowed the important detection of problems with data quality and provided some insight into how the impacts varied with different data assimilation techniques. The use of variational and DFS techniques complement conventional OSEs that rely on assessing the impact of observational datasets through comparing multiple simulations with and without the inclusion of different observational streams. The variational and DFS techniques, however, avoid the use of multiple simulations necessary in OSEs, which can be quite resource intensive and time consuming, especially if the contributions of several different observing systems are assessed.

THORPEX also explored the impact of potentially new observing systems on forecast skill, including evaluating Doppler lidar wind observations taken during A-TREC and water vapor measurements provided by differential absorption lidar (DIAL) during T-PARC. Specifically, the Harnisch et al. (2011) study showed that the impacts of the water vapor measurements in T-PARC were generally small but could be large in certain circumstances, while Weissmann and Cardinali (2007) provided encouraging results for impacts of lidar wind measurements during A-TREC. Wind measurements from spaceborne remote sensing systems will soon be introduced by the European Space Agency (ESA)'s Atmospheric Dynamics Mission. Further support for wind observations from space are described in Baker et al. (2014). These studies utilized observing system simulation experiments (OSSEs) to assess data impact where "virtual observations" are created by adding simulated observational noise to fields taken from a high-resolution "nature simulation" that is meant to depict the true state of the atmosphere. Successful OSSEs require accurate introduction of errors and performance limitations in the simulated observations and a careful calibration of the OSSE system, such that the impact of existing observations on forecast skill is accurately represented. The ECMWF, the THORPEX effort funded by the NOAA in the United States, and the Joint Center for Satellite Data Assimilation contributed to the development of this carefully calibrated OSSE system (e.g., Matsutani et al. 2007).

Data assimilation research. One factor central to the steady improvement in NWP forecasts is the more accurate initial conditions resulting from advances in data assimilation techniques. The early THORPEX data assimilation efforts are described in Rabier et al. (2008). One major accomplishment was the THORPEX role in the maturing of ensemble-filtertype data assimilation systems that incorporate model uncertainty into data assimilation systems through the utilization of ensemble-based background error covariance information. Prior to THORPEX, researchers had been utilizing variational data assimilation techniques in operational NWP and demonstrating the advantages of ensemble Kalman filters in simplified models. The ability of ensemble-based data assimilation to improve operational global analyses and forecasts was demonstrated by Whitaker et al. (2008) through funding by the NOAA THORPEX program. 
More recent approaches have attempted to bridge the gap between variational techniques and ensemble-based systems through hybrid assimilation systems where the background error covariances in the variational system are defined as flowdependent estimations obtained from an ensemble of background states. One approach undertaken at Météo-France and ECMWF is to utilize an ensemble of analyses created by perturbing the observations and rerunning the four-dimensional variational assimilation system providing consistency with the deterministic models for those centers employing the four-dimensional variational approach (Berre and Desroziers 2010; Bonavita et al. 2012). Investigations into the optimal filtering of ensemble variances and on the modeling of flow-dependent covariances using wavelets have supported this approach. Alternatively, the ensemble background states can also be produced by an ensemble Kalman filter or its simplified variants in what is called the hybrid ensemble-variational approach. Over the past decade, and in part through THORPEX funding, hybrid data assimilation has grown substantially from fundamental algorithm development to more recent implementation of these techniques in regional and global NWP systems (e.g., Clayton et al. 2013; Kuhl et al. 2013; Wang et al. 2013).

Studies suggest that these hybrid ensemblevariational systems should be able to leverage the strengths of both the ensemble Kalman filter and variational systems, producing an analysis that is potentially superior to either approach. THORPEX-sponsored workshops such as the 2008 WWRP/THORPEX Workshop on 4D-Variational and Ensemble Kalman Filter Intercomparisons were instrumental in facilitating collaborations, intercomparisons, and hybridizations of assimilation methods. THORPEX has also been instrumental in improving the definition of the terms used in data assimilation as the number of schemes and especially hybrids have begun to proliferate (e.g., Lorenc et al. 2015).

Ensemble prediction and TIGGE. The THORPEX Interactive Grand Global Ensemble (TIGGE) archive (Bougeault et al. 2010; Swinbank et al. 2016) was established to support the THORPEX goal of extending forecast skill into week 2 through research on ensemble prediction. TIGGE is a research archive consisting of data from 10 operational global ensemble prediction systems (EPSs), including the analyses, the control simulation, and the perturbed ensemble members. Data are made available $\sim 48 \mathrm{~h}$ after the forecasts are completed. TIGGE resulted from an unprecedented cooperation between operational centers and between the research and operational communities in order to agree upon and implement a common set of variables, pressure levels, formats, standards, and analysis tools. The path for transmission and archival of the hundreds of terabytes $\left(10^{12}\right.$ bytes) of data requested by users each year is described in Bougeault et al. (2010). TIGGE relies upon generous support from the modeling centers and the three archival centers at the ECMWF, NCAR, and the Chinese Meteorological Administration. The usage of the TIGGE database has increased gradually over the years, with regular monthly usage statistics at the three centers suggesting that typical usage approaches $\sim 150$ active users each month. TIGGE has over 3,000 registered users. A summary of the TIGGE users in Fig. 7 illustrates the broad international reach of the project.

Our discussion will be quite brief, since the history, accomplishments, and goals of TIGGE were recently described in Swinbank et al. (2016). The TIGGE research areas are strikingly broad and include, but are not limited to, 1) ensemble verification; 2) generation and evaluation of multimodel ensembles formed through combining the individual global ensemble systems within the archive; 3) ensemble calibration from statistical postprocessing; 4) studies into the dynamics and predictability of middle latitude processes, such as extratropical cyclones, storm tracks, blocking, and jet stream variability; 5) improved prediction and understanding of tropical cyclones and their extratropical transition; and 6) investigations related to advancing knowledge and improving prediction of the MJO. This research also revealed several challenges in NWP, such as the Gray et al. (2014) study that indicated that all the models in TIGGE were unable to maintain realistically tight potential vorticity gradients along the jet stream in the face of model dissipation and the work of Froude (2010) that showed that all models underpredicted the propagation speed of extratropical cyclones. Within North America, TIGGE has proved useful for studies of model performance and the dynamics of major, high-impact weather such as Hurricane Sandy and the 2013 Colorado Front Range floods. TIGGE is a research archive with data available $\sim 48 \mathrm{~h}$ after the simulations are completed. The North American Ensemble Forecast System (NAEFS) is an operational system that parallels several aspects of TIGGE. NAEFS was motivated in large part by THORPEX (Candille 2009) and will be discussed in more detail in a subsequent paper that focuses on the legacies of THORPEX.

The prediction of high-impact weather on a local scale requires the use of higher-resolution forecasts 
than are currently available from global models so that the research and operational vision is becoming increasingly focused on convective-permitting ensembles (e.g., Stensrud et al. 2009). In response to this vision, THORPEX brought together a panel of experts with the goal of establishing a TIGGElike archive composed of high-resolution, limitedarea models (LAMs) called TIGGE-LAM. To date, a TIGGE-LAM database has only been established for Europe and is hosted by the ECMWF with funding support from the European GEOSS Interoperability for Weather, Ocean and Water (GEOWOW) project (a European Commission-funded project that is led by the ESA). Data in this TIGGE-LAM archive are currently available from seven European ensemble systems at horizontal resolutions from 2 to $10 \mathrm{~km}$, with plans to grow to a 10 -system archive. TIGGELAM furthers research into the optimal design of high-resolution, limited-area ensemble systems while providing a mechanism for detailed comparisons of the performance of different systems. A LAM archive is potentially quite valuable, since these various models often have different spatial domains with varying resolution so that, unlike global models, systematic comparisons of LAM systems are often lacking. Within North America, an alternative

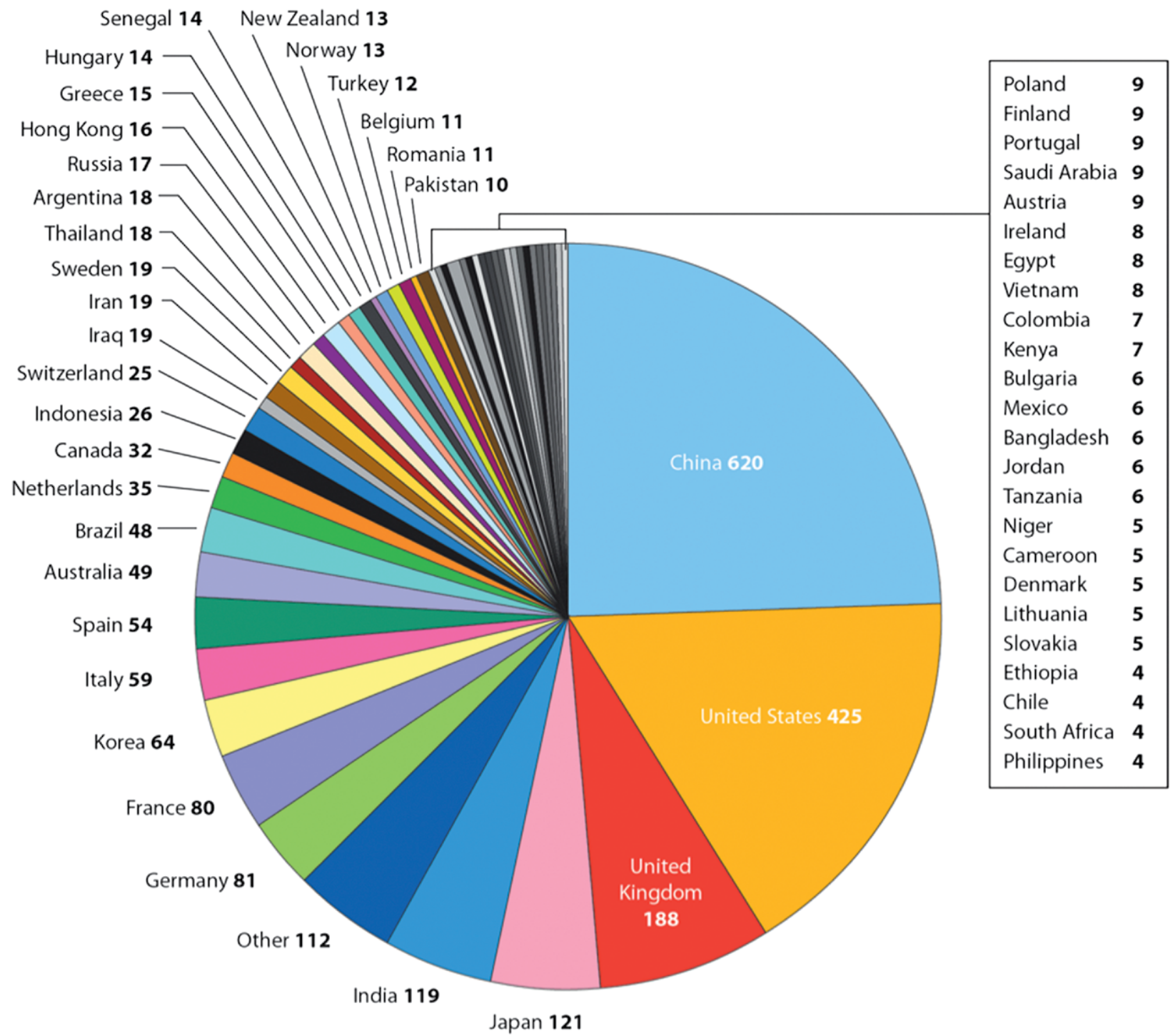

FIG. 7. The nationalities of the registered users of the TIGGE archive at the ECMWF as per a survey conducted in 2013. Since registered users do not always become frequent users, this pie chart should be considered along with other metrics, such as active users and publications. Note that only nations with four or more registered users are shown. The sum of users in the category of nations with less than four users is shown in the category of "Other," which has 112 users. Image courtesy of Manuel Fuentes and colleagues at the ECMWF. 
approach for research on convective-permitting ensembles occurs during the U.S. Hazardous Weather Testbed's spring experiment (e.g., Clark et al. 2012) jointly managed by NOAA's Storm Prediction Center and the National Severe Storms Laboratory. The spring experiment, however, is limited to approximately five weeks each year.

\section{REGIONAL ASPECTS OF HIGH-IMPACT} WEATHER SYSTEMS. The THORPEX effort included a series of field campaigns designed to advance knowledge of how global-to-regional processes lead to high-impact weather events.

High-impact weather in the Mediterranean basin. HyMeX is a 10-yr (2010-20) international concerted experimental and modeling effort aimed at improving knowledge of the water cycle in the Mediterranean basin, with an emphasis on high-impact weather events, through monitoring and modeling of the coupled system (land, sea, and atmosphere) from very short range forecasts to climate scales (www.hymex .org; Drobinski et al. 2014). Although much larger in scope, HyMeX can be considered to be rooted in the THORPEX program, as HyMeX was designed in part as a follow-on to the earlier THORPEX/MEDEX project (Jansa et al. 2014). The Scientific Steering Committee of the WWRP and THORPEX ICSC also endorsed HyMeX.

The HyMeX observational strategy included a 10-yr effort over the whole Mediterranean, an enhanced observation period (2012-15) over the western Mediterranean, and two major field campaigns that took place from September 2012 to midMarch 2013. The first field campaign (Ducrocq et al. 2014) was dedicated to heavy precipitation and flash floods that frequently affect the area during autumn and cause casualties and several hundreds of millions of dollars in annual losses. This campaign took place over the northwestern Mediterranean Sea and the nearby coastal regions in France, Italy, and Spain. The hydrological measurements performed over two French catchments during this first campaign have been repeated each autumn through 2015 as part of the enhanced observation period (Braud et al. 2014). The second campaign, a late winter 2013 field campaign, was dedicated to intense air-sea fluxes primarily under cold and dry regional strong winds and the associated dense water formation and ocean convection in the Gulf of Lyon (northwestern Mediterranean Sea). The observations collected by about 250 research instruments during the two efforts constitute an unprecedented atmospheric, ocean, and land surfaces datasets, allowing the study of the interactions and feedbacks between the different components of the hydrological cycle during heavy precipitation and flash floods as well as during strong winds and ocean convection events.

HyMeX research has advanced knowledge of those synoptic and mesoscale conditions that favor flash floods and heavy precipitation events, including how the Mediterranean Sea and air-sea fluxes, coastal mountains and island orography, and hydrological processes interplay to produce flooding. HyMeX also provides a framework for improving convectionpermitting NWP, physical parameterizations, data assimilation, ensemble systems, and the coupling of ensemble systems with hydrological models. HyMeX observations have also helped to evaluate the utility of both potentially new and existing operational observations, while allowing preparation for satellite missions such the NASA GPM mission. HyMeX also addressed the development and evaluation of regional climate modeling systems that couple ocean, atmosphere, and river systems, including projections for the joint HyMeX and WCRP/Coordinated Regional Climate Downscaling Experiment (CORDEX) CMIP5 downscaling exercise over the Mediterranean domain. Social responses to extreme precipitation and associated hydrological events were also investigated following, among other approaches, an interdisciplinary postflood methodology (Ruin et al. 2014).

West African monsoon. AMMA was launched in 2002 as an international interdisciplinary research program concerned with the variability of the West African monsoon (WAM) and its impacts across daily to interannual time scales (Redelsperger et al. 2006). The large international AMMA program delivered an unprecedented multiscale, multidisciplinary database utilized across the world and mirrored in Africa. AMMA measurements included the deployment of long-term observational systems beginning in 2001 and field campaigns between 2005 and 2007 with several intensive observation periods. AMMA has five working groups aimed at different aspects of the program, including a working group on high-impact weather that closely collaborated with THORPEX. Highlights of this collaboration included research on predictability studies, OSEs, and efforts to evaluate and subsequently tailor forecast products for use in western Africa. AMMA has made significant progress in advancing our knowledge of the key weather systems in the WAM, including mesoscale convective systems (MCSs), African easterly waves (AEWs), and 
Kelvin waves. Improvements have also been realized in our understanding of tropical-extratropical interactions and the relationship between African weather systems and downstream tropical cyclogenesis. A special collection in AMS journals was devoted to the nature and predictability of these weather systems.

An important question for prediction over West Africa is the potential advances in forecasts through improvements in data quality. A significant effort was made to remove a moisture bias (Agustí-Panareda et al. 2009; Nuret et al. 2008) in the radiosonde data and employ the corrected dataset to reveal significant positive impacts of the extra AMMA soundings on the representation of WAM, including the African easterly jet. Karbou et al. (2010) also showed how assimilation of satellite microwave measurements on continental surface can dramatically correct humidity errors in the analyses and hence improve weather forecasts in the West African region. This approach was evaluated against the in situ AMMA measurements, showing dramatic improvement of diurnal cycle. Unfortunately, the impact of these new data (soundings and satellite data) on the forecasts was found to degrade after $24 \mathrm{~h}$ because of the significant biases resulting from the model physics.

AMMA and the AMMA-THORPEX collaboration also demonstrated that AEWs are usually triggered by convection over upstream topography and subsequently intensify in association with embedded MCSs. These studies also reveal that forecasts depend on both the basic state and the diabatic processes associated with convection. Unfortunately, significant variability is observed in the representation of AEWs in the analyses and forecasts provided by various operational modeling systems so that very little skill is evident in forecasts of these systems beyond $\sim 2$ days. At short lead times ( 2 days), the forecasts are most sensitive to the midlevel meridional winds (i.e., the location of the AEW trough), while at long lead times (5 days) forecasts are most sensitive to midtropospheric errors in equivalent potential temperature and subsequent errors in convection.

AMMA and NASA AMMA (NAMMA) investigated the relationship between AEWs and downstream tropical cyclogenesis. The findings show that the nature of the AEW, including its embedded MCSs, can impact the probability of downstream cyclogenesis (e.g., Hopsch et al. 2010), while the advection of dry air can be a hindrance to tropical cyclogenesis just downstream of West Africa. The THORPEX-AMMA effort also contributed to understanding model biases associated with the treatment of the dry-air layer over the subtropical-air layer, as Drobinski et al. (2013) used driftsonde data to reveal large errors in the model-predicted temperature over the subtropical Atlantic in the vicinity of Saharan-dust layers likely due to the operational models not representing the impacts of dust on the shortwave radiative transfers.

THORPEX T-PARC. The international T-PARC research initiative addressed the dynamics and short-range prediction of weather systems over the eastern Asian and the western North Pacific and the impact of these systems on the dynamics and medium-range prediction over the "downstream" regions such as the eastern North Pacific and North America. The strong dynamical links between these regions occur via upper-tropospheric wave packets along the primary midlatitude waveguides that can be invigorated by subsequent downstream cyclogenesis events. The focus for the "upstream" region was tropical cyclones and other types of convection and their extratropical transition, which can trigger high-impact weather events over the downstream regions, including intense extratropical cyclones; orographic precipitation; floods; severe weather; and hot, dry winds that increase the risk of wild fires and the severity of droughts.

T-PARC had winter and summer field phases, with the latter attracting international partnership among several national programs and cosponsorship with efforts within the broader WWRP and WMO Tropical Cyclone Program. These national programs and their sponsors included 1) Tropical Cyclone Structure-2008 (TCS-08; United States), 2) Typhoon Hunter-2008 (TH-08; Japan), 3) Predictability and Observation Experiment (PROBEX; South Korea), and 4) the Tibetan Plateau Experiment (China) and the South China Sea Experiment (China). In addition, measurements were taken during summer T-PARC by the Dropsonde Observations for Typhoon Surveillance (DOTSTAR) effort in the vicinity of the Taiwan region.

These collective programs allowed three observational strategies:

1) a tropical measurement strategy that examined circulations within the tropical western North Pacific monsoon environment as they related to enhanced and reduced periods of widespread deep convection, tropical cyclone formation, tropical cyclone intensification, and tropical cyclone structure change;

2) a targeted observation measurement strategy focused on identification of regions in which extra 
observations may reduce numerical forecast error growth in forecasts of tropical cyclone tracks over the western North Pacific; and

3) a measurement strategy for extratropical transition and the associated downstream impacts based on observing the poleward movement of decaying tropical cyclones and the resulting intense cyclogenesis that results from its interaction with the midlatitude circulation.

These strategies of the summer phase of T-PARC combined into a complete tropical-to-extratropical measurement effort (Fig. 8) that utilized four research aircraft.

A key aspect of the tropical component of the T-PARC/TCS- 08 collaboration was defining the relative roles of different processes during tropical cyclone formation, such as preexisting circulations, variations of water vapor in middle levels, and the organization of low-level vorticity in deep convective towers versus midlevel circulations embedded in stratiform regions of MCSs. These analyses were also considered within the context of dynamical theories for the genesis of tropical cyclones, the framework of current and future space-based observing systems, and the goal of identifying barriers to improved prediction. Variations in the structure of mature tropical cyclones were also examined through aircraft missions in storms of varying intensity, with special emphasis placed on observations of the outer-rainband structures and formation of secondary eyewalls. This research provides new insight pertaining to the importance of boundary layer and air-ocean processes and their representation in numerical models.

T-PARC also provided for the evaluation of a variety of methods to determine sensitive areas with calculations produced by nine different operational centers and research groups. New targeting capabilities explored during T-PARC included the first application of the Eurorisk Preview data targeting system to tropical cyclone prediction and defining several common verification areas for detecting changes in predictive skill for both tropical cyclones and their downstream impacts. The results from experiments indicate that impacts of targeted observations for tropical cyclone track prediction vary greatly with observation type, data assimilation system, and forecast model. For example, while statistically significant improvements in tropical cyclone track forecasts were achieved in the NCEP GFS global model, the improvements in the ECMWF and Japan Meteorological Agency (JMA) model forecasts were smaller (Weissmann et al. 2011; Chou et al. 2011). The relative

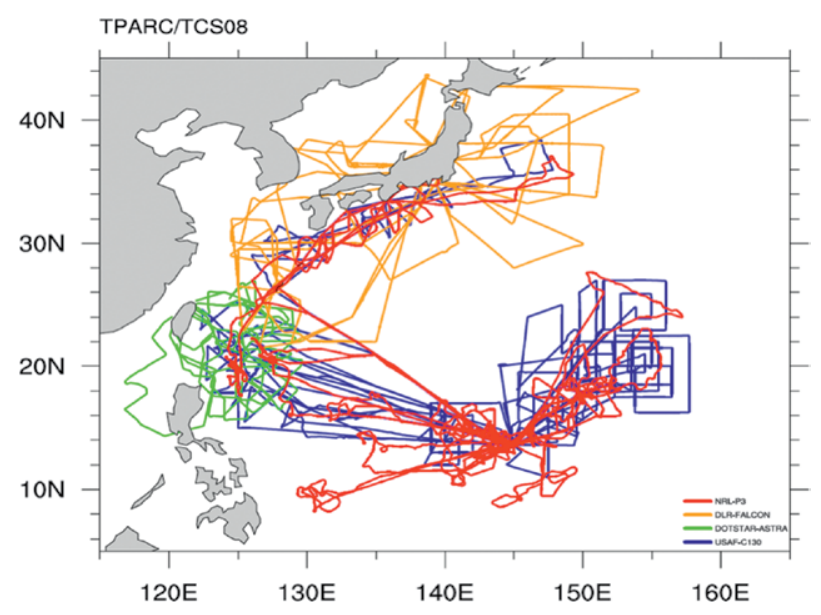

FIG. 8. Tracks of all aircraft flights during the T-PARC field program. The measurements of tropical cyclone systems spanned from genesis to their extratropical transition.

contributions of different in situ observations were also investigated along with the relative impacts of satellite-derived atmospheric motion vectors.

During the field phase of T-PARC, several tropical disturbances moved poleward to undergo a transition into a midlatitude system. The tropical disturbances sampled included a weak circulation associated with widespread deep convection, a small-scale tropical cyclone, a typhoon, and a super typhoon. These systems were associated with a wide range of predicted and observed extratropical transitions and downstream developments. For example, Typhoon Sinlaku moved into and interacted with the midlatitude circulations, and forecasts from operational global models began to exhibit decreased predictability (e.g., increased variability in the ensemble) downstream over the central and eastern North Pacific (Keller et al. 2011; see Fig. 4). This increased variability was consistently observed over the central North Pacific between $160^{\circ} \mathrm{E}$ and $160^{\circ} \mathrm{W}$, with subsequent relative maxima occurring downstream at intervals of approximately $40^{\circ}$ longitude. The process of downstream development has been found to often occur in association with the ET of tropical cyclones over the western North Pacific (Harr and Dea 2009; Keller et al. 2014).

The main objective of the winter phase of T-PARC was to understand how perturbations from the tropics, Eurasia, and polar fronts evolve through the westerly waveguide and turn into high-impact winter weather events over North America. Extra soundings from the Russian radiosonde network, as well as dropsonde observations made from three manned aircraft (NOAA's Gulfstream-IV and two U.S. Air 
Force C-130s) were collected in an adaptive manner to improve forecasts for 2009 winter weather events over North America. Nonadaptive aircraft measurements over the Pacific Rim and part of India deployed through the European Meteorological Network (EUMETNET)-Aircraft Meteorological Data Relay (AMDAR) program enhanced the observational coverage. Winter T-PARC was led by NOAA with participation from agencies and universities across the United States, Canada, Mexico, Japan, ECWMF, and Russia. Observational data were assimilated by operational centers to improve real-time numerical weather prediction, and post-field study investigations are ongoing.

SOCIETAL AND ECONOMIC RESEARCH AND APPLICATIONS. The intentional emphasis of THORPEX to apply scientific achievements to societal problems through focusing on high-impact events and the desire to better understand the value that forecast improvements have or could yield separates THORPEX from most previous major weather programs. THORPEX envisioned ambitious activities carried out by a Societal and Economic Research and Applications (SERA) working group. A schematic conceptualizing the flow of information and benefits (Fig. 9) shows that many of the important foci for social and economic research have less to do with the quality of the weather prediction and much more to do with communication and decision processes that affect perceptions, behavior, and outcomes, points that remain as relevant today as when first postulated (Lazo 2012).

The main accomplishment of the SERA effort was engendering a broader recognition among the physical science community that social science research and applications play an important role in directing and providing the context for prediction research (e.g., Shapiro et al. 2010). This recognition was evident within THORPEX itself, as one of the first steps of the working group was to change its name from the Societal and Economic Application (SEA; see Fig. 2, top) to SERA, which included an $\mathrm{R}$ for research, clearly indicating that solving the problems in this area put forth by THORPEX required social science and economics research. The importance of SERA was apparent within activities and membership of the THORPEX regional committees, including those for Africa (Roehrig et al. 2008; Diongue-Niang et al. 2008), the Southern Hemisphere (McBride et al. 2006), Europe (Craig et al. 2010), Asia (Asian THORPEX Regional Committee 2014), and North America (Morss et al. 2008). For most regional committees, tangible input from SERA included contributions to regional workshops, inventories of high-impact weather events, and analyses of relevant social and economic impacts, such as those synthesized from the Munich Re global natural catastrophe loss database. Some regions made additional tangible advances. For example, SERA priorities were developed for the North American THORPEX program through a multiday workshop, a series of white papers, and journal articles (Morss et al. 2008), providing an extra impetus and justification for subsequent social or interdisciplinary research with additional workshops in both the United States and Canada (e.g., Mills et al. 2008; Davison et al. 2012). Partly inspired by this work, NOAA subsequently launched its "Weather-Ready Nation" and Forecasting a Continuum of Environmental Threats (FACETs) initiatives. SERA efforts were also associated with THORPE regional campaigns, such as the social responses to extreme precipitation and associated hydrological events investigated during HyMeX (Ruin et al. 2014), and AMMA contributions toward meeting the needs for public health, food security, and water resources in West Africa. The AMMA efforts are summarized in a special issue of Atmospheric Science Letters (2011, Vol. 12, No. 1) entitled "African Monsoon Multidisciplinary Analysis (AMMA): An integrated project for understanding of the West African climate system and its human dimension."

THORPEX itself was a focal point for SERA activities, drawing over 75 unique SERA paper contributions that were submitted to the three THORPEX International Science symposia convened during the program. International, regional, and national THORPEX working group members also provided important contributions to the International Conference on Secure and Sustainable Living: Social and Economic Benefits of Weather, Climate and Water Services held March 2007 in Madrid, Spain (WMO 2007a,b), and to the increasing prominence of social science with sessions at major meteorological conferences from the annual meetings of the AMS and town halls on THORPEX and the U.S. THORPEX program to the recent (August 2014) World Weather Open Science Conference (WWOSC), where over 20 sessions and 100 speakers dealt with SERA-related themes. SERA presentations were also made to a diverse range of nonmeteorological audiences (e.g., the Second World Conference on Disaster Reduction, the Property Claims Service Annual Conference, and the Integrated Research for Disaster Risk program).

Unfortunately, the SERA component of THORPEX was unable to obtain the significant, focused funding 
levels, which limited the scope of their activities. It was not until late in the program, when SERA activities were moved under the auspices of the larger WWRP, that the SERA Working Group was able to realize a truly diverse membership of social scientists (e.g., economics, psychology, and geography) and representatives from weather sensitive sectors and operational centers. As THORPEX enters into a legacy phase, a remaining challenge for the WWRP is to self-reflect in a more formal way, including taking advantage of social science to trace and evaluate

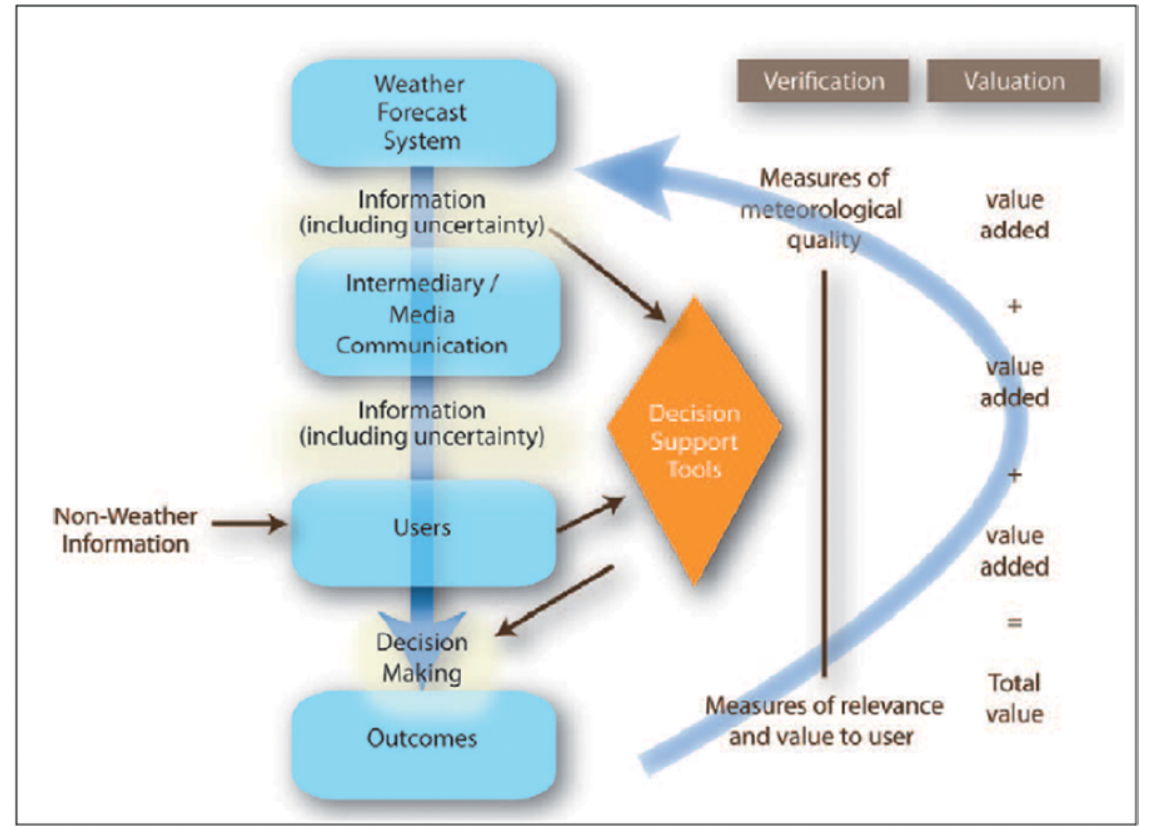

Fig. 9. Simplified model of the flow of information from forecast creation to value realization (source: Morss et al. 2008). the impact of a decade of

scientific progress upon research and development activities, operational forecasting centers, users of weather information, and ultimately to societal benefits. This self-reflection should also address why the SERA activities were limited and what strategies should be implemented in order to expand future SERA activities, such as the THORPEX legacy projects and the Weather-Ready Nation. These projects may face an easier path forward given 1) that a growing network of social and interdisciplinary scientists focused on weather-related subjects and cases now exists, as evidenced by substantial representation at the recent WWOSC and 2) greater recognition of the increasing importance, rigor, and utility of such research, as indicated in improved impact factors of established applied journals that include, but are not limited to, SERA topics (e.g., the 5-yr impact factor of Meteorological Applications improved from 0.626 to 1.783 from 2007 to 2012) and the emergence of new journals dedicated to interdisciplinary weather research (e.g., the AMS journal Weather, Climate, and Society). These advances indicate that the reach, quantity, and quality of SERA-related publications and scientists have all increased since the inception of THORPEX.

SUMMARY. This paper focused on the scientific accomplishments of THORPEX, while a future paper will focus on the legacies of THORPEX, including traceable improvements in forecast skill, paradigm shifts in research collaborations, and the development of newly proposed THORPEX legacy projects. THORPEX science represents the intersection of challenging fundamental research, with an underlying goal of advancing predictive skill and the enhanced utilization of weather products. The THORPEX approach provided unprecedented access of the academic research community to those operational products that have the potential to advance basic and applied research.

One set of THORPEX outcomes was associated with regional campaigns focused on striving to advance knowledge and improve prediction on high-impact weather events, such as heavy rainfall embedded in the West African monsoon, flash floods in the Mediterranean basin, typhoons that impact the western Pacific and eastern Asia, and downstream events driven by Rossby wave responses to the extratropical transition of these typhoons. A second outcome was progress on some of the most challenging problems in the global atmospheric system, such as the representation of tropical convection and its role in the global system, advancing understanding and prediction of polar processes, and addressing the interplay between high-impact weather and the perturbations that excite the midlatitude waveguide. A third outcome of THORPEX was a greater focus on the components of the predictive system itself from the design of the global observing system to the development 
and testing of new data assimilation approaches and efforts to advance ensemble prediction. In terms of the examples provided in the initial motivation of THORPEX, successes included meeting the goals of better understanding the interplay between Rossby wave dynamics and high-impact weather, improvements in representing the flow dependency in data assimilation systems, understanding the impacts of targeting on forecast skill, and improved utilization of ensemble prediction through TIGGE.

This article, the references in the online supplement, and the special journal issues/collections describing THORPEX research indicate that the project has been a resounding success through making a real difference to weather science and prediction research. Perhaps even more significantly, THORPEX marks a turning point in the collaboration and integration of the operational NWP and forecasting agencies with the academic and wider research communities. This collaboration also clearly illustrates that numerous challenging and fundamental research problems still remain in the area of prediction science. THORPEX has also paved the way for ongoing efforts to bring together physical scientists with researchers in the areas of social, economic, and applied research and for research at the intersection of weather and climate.

ACKNOWLEDGMENTS. There are numerous people to thank in a 10 -yr program that was preceded with multiple years of planning, and we will undoubtedly leave out many key contributors. We wish to thank the current and past members of the THORPEX ICSC, Working Groups, and Regional Committees. While the current membership list can be found on the WWRP website, we wish to acknowledge several researchers and administrators heavily involved in the early THORPEX efforts, including Kamil Puri (Australia), Carla Cardinali (ECMWF), Walter Dabberdt (Vaisala), Jeff Lazo (NCAR), Chris Velden (U Wisc), Ulrich Schumann (DWD), De Hui Chen (China), and David Richardson (ECMWF). We also thank Alan Dickinson (Met Office) for his guidance as Chair of the THORPEX ICSC from November 2008 until the end of the program and Rick Rosen (NOAA) for serving as acting Chair of the ICSC for approximately one year and his other contributions to the international program and the U.S. THORPEX effort. Louis Uccellini is acknowledged as a tireless force for THORPEX within the United States and for the international program including the establishment of the international THORPEX Project Office and the U.S. efforts. Martin Miller (ECMWF) and members of the Working Group on Numerical Experimentation are greatly appreciated for their involvement in THORPEX and their guidance on numerical modeling issues. We also would like to thank those involved in organizing the symposium of THORPEX, especially Hans Volkert (DLR) and James Hansen (NRL) for chairing the Second and Third Science Symposiums, respectively. We acknowledge Celeste Saulo (Argentina) for her efforts in organizing the THORPEX activities in South America. We also wish to thank Rit Carbone and Keith Browning, who had the vision of a THORPEX programme in the WWRP, and Bob Gall for early leadership.

We gratefully acknowledge the support from the donor nations and all those programs that supported THORPEX. We also wish to thank Louis Uccellini, David Rogers, and Pai-Yei Whung, who guided the program through NOAA, leading to early funding. David Rogers was also the first chair of the U.S. interagency working group. Louis Uccellini, in particular, also devoted countless hours to THORPEX over its lifetime. We also wish to thank Jay Fein, the late Jarvis Moyers, and Steve Nelson, all of NSF, and Ramesh Kakar and Jack Kaye of NASA for their early support of THORPEX experiments and later projects such as YOTC. We acknowledge the support of the WMO, particularly Elena Manaenkova Alexandra Frolov, and Zheng Guoguong, who recognized the early potential of THORPEX. In addition to his role in the WMO, Jerry Langoasa also played a role in the early design of the experiment and provided insight on how to reach the developing nations of the world as an early representative of THORPEX in South Africa, and Nathalie Tournier provided administrative support for the many meetings and all of the documents of THORPEX. The lead author wishes to thank NOAA, NSF, NASA and NCAR for their support of his administrative role in THORPEX including their support of the US THORPEX Project Office. His scientific role was supported with the following grants: NSF-AGS 0621545/0652462 and NSF/PLR 0733007/1143790. Finally, we thank all those involved in THORPEX and apologize for any omissions in the list of important contributions.

\section{REFERENCES}

Agustí-Panareda, A., and Coauthors, 2009: Radiosonde humidity bias correction over the West African region for the special AMMA reanalysis at ECMWF. Quart. J. Roy. Meteor. Soc., 135, 595-617, doi:10.1002 /qj.396.

Anderson, J., T. Hoar, K. Raeder, H. Liu, N. Collins, R. Torn, and A. Arellano, 2009: The data assimilation research 
testbed: A community data assimilation facility. Bull. Amer. Meteor. Soc., 90, 1283-1296, doi:10.1175 /2009BAMS2618.1.

Asian THORPEX Regional Committee, 2014: Asian THORPEX implementation plan. WMO, 8 pp. [Available online at www.wmo.int/pages/prog/arep /wwrp/new/documents/asian_implementation_plan .pdf.]

Baker, W. D., and Coauthors, 2014: Lidar-measured wind profiles: The missing link in the global observing system. Bull. Amer. Meteor. Soc., 95, 543-564, doi:10.1175/BAMS-D-12-00164.1.

Berre, L., and G. Desroziers, 2010: Filtering of background error variances and correlations by local spatial averaging: A review. Mon. Wea. Rev., 138, 3693-3720, doi:10.1175/2010MWR3111.1.

Boettcher, M., and H. Wernli, 2013: A 10-yr climatology of diabatic Rossby waves in the Northern Hemisphere. Mon. Wea. Rev., 141, 1139-1154, doi:10.1175/MWR -D-12-00012.1.

Bonavita, M., L. Isaksen, and E. Hólm, 2012: On the use of EDA background error variances in the ECMWF 4D-Var. Quart. J. Roy. Meteor. Soc., 138, 1540-1559, doi:10.1002/qj.1899.

Bougeault, P., and Coauthors, 2010: The THORPEX Interactive Grand Global Ensemble (TIGGE). Bull. Amer. Meteor. Soc., 91, 1059-1072, doi:10.1175 /2010BAMS2853.1.

Braud, I., and Coauthors, 2014: Multi-scale hydrometeorological observation and modelling for flash-flood understanding. Hydrol. Earth Syst. Sci., 18, 3733-3761, doi:10.5194/hess-18-3733-2014.

Candille, G., 2009: The multiensemble approach: The NAEFS example. Mon. Wea. Rev., 137, 1655-1665, doi:10.1175/2008MWR2682.1.

Cardinali, C., S. Pezzuli, and E. Andersson, 2004: Influence of matrix diagnostic of a data assimilation system. Quart. J. Roy. Meteor. Soc., 130, 2767-2786, doi:10.1256/qj.03.205.

Cavallo, S. M., J. Berner, and C. Snyder, 2016: Diagnosing model errors from time-averaged tendencies in the Weather Research and Forecasting (WRF) Model. Mon. Wea. Rev., 144, 759-779, doi:10.1175/MWR-D -15-0120.1.

Chapnik, B., G. Desroziers, F. Rabier, and O. Talagrand, 2006: Diagnosis and tuning of observervational error statistics in a quasi operational data assimilation setting. Quart. J. Roy. Meteor. Soc., 132, 543-565, doi:10.1256/qj.04.102.

Chou, K.-H., C.-C. Wu, P.-H. Lin, S. D. Aberson, M. Weissmann, F. Harnisch, and T. Nakazawa, 2011: The impact of dropwindsonde observations on typhoon track forecasts in DOTSTAR and
T-PARC. Mon. Wea. Rev., 139, 1728-1743, doi:10.1175 /2010MWR3582.1.

Chung, Y.-C., S. Bélair, and J. Mailhot, 2010: Simulation of snow on Arctic sea ice using a coupled snow-ice model. J. Hydrometeor., 11, 199-210, doi:10.1175 /2009JHM1112.1.

,-- , and,- 2011 : Blowing snow on Arctic sea ice: Results from an improved sea-ice, snow and blowing-snow coupled system. J. Hydrometeor., 12, 678-689, doi:10.1175/2011JHM1293.1.

Clark, A. J., and Coauthors, 2012: An overview of the 2010 Hazardous Weather Testbed Experimental Forecast Program Spring Experiment. Bull. Amer. Meteor. Soc., 93, 55-74, doi:10.1175/BAMS-D-11-00040.1.

Clayton, A. M., A. C. Lorenc, and D. M. Barker, 2013: Operational implementation of a hybrid ensemble/4D-Var global data assimilation system at the Met Office. Quart. J. Roy. Meteor. Soc., 139, 1445-1461, doi:10.1002/qj.2054.

Cohn, S., and Coauthors, 2013: Driftsondes: Providing in-situ long-duration dropsonde observations over remote regions. Bull. Amer. Meteor. Soc., 94, 16611674, doi:10.1175/BAMS-D-12-00075.1.

Craig, G., and Coauthors, 2010: Weather research in Europe: A THORPEX European plan, version 3.1. WMO/TD-1531, WWRP/THORPEX 14, 45 pp. [Available online at www.wmo.int/pages/prog/arep /wwrp/new/documents/European_Plan_web.pdf.]

Davies, H. C., and M. Didone, 2013: Diagnosis and dynamics of forecast error growth. Mon. Wea. Rev., 141, 2483-2501, doi:10.1175/MWR-D-12-00242.1.

Davison, M., A. Gurtuna, C. Masse, and B. Mills, 2012: Factors affecting the value of environmental predictions to the energy sector. Environ. Syst. Res., 1, 4, doi:10.1186/2193-2697-1-4.

Deacu, D., A. Zadra, and J. Hanesiak, 2010: Simulating wind channeling over Frobisher Bay and its interaction with downslopewinds during the 7-8 November 2006 wind event. Atmos.-Ocean, 48, 101-121, doi:10.3137/AO1109.2010.

Dee, D. P., and Coauthors, 2011: The ERA-Interim reanalysis: Configuration and performance of the data assimilation system. Quart. J. Roy. Meteor. Soc., 137, 553-597, doi:10.1002/qj.828.

Diongue-Niang, A., and Coauthors, 2008: WWRP/ THORPEX African Implementation Plan: Version 1. WMO/TD-1461, WWRP/THORPEX 11, 33 pp. [Available online at www.wmo.int/pages/prog /arep/wwrp/new/documents/thorpex_african _implementation_plan.pdf.]

Drobinski, P., and Coauthors, 2013: Driftsonde observations to evaluate numerical weather prediction of the late 2006 African monsoon. J. Appl. 
Meteor. Climatol., 52, 974-995, doi:10.1175/JAMC -D-11-0176.1.

— ciplinary program on the Mediterranean water cycle. Bull. Amer. Meteor. Soc., 95, 1063-1082, doi:10.1175 /BAMS-D-12-00242.1.

Ducrocq, V., and Coauthors, 2014: HyMeX-SOP1: The field campaign dedicated to heavy precipitation and flash flooding in the northwestern Mediterranean. Bull. Amer. Meteor. Soc., 95, 1083-1100, doi:10.1175 /BAMS-D-12-00244.1.

Federal Highway Administration, 2014: How do weather events impact roads? Accessed 26 May 2016. [Available online at http://ops.fhwa.dot.gov/weather /q1_roadimpact.htm.]

Froude, L. S. R., 2010: TIGGE: Comparison of the prediction of Northern Hemisphere extratropical cyclones by different ensemble prediction systems. Wea. Forecasting, 25, 819-836, doi:10.1175 /2010WAF2222326.1.

Garand, L., O. Pancrati, and S. Heilliette, 2011: Validation of forecast cloud parameters from multi-spectral AIRS radiances from multispectral AIRS radiances. Atmos.-Ocean, 49, 121-137, doi:10.1080/07055900 .2011 .567379

Gelaro, R., R. H. Langland, S. Pellerin, and R. Todling, 2010: The THORPEX Observation Impact Intercomparison Experiment. Mon. Wea. Rev., 138, 4009-4025, doi:10.1175/2010MWR3393.1.

Gray, S. L., and H. Wernli, 2015: Dynamics and predictability of middle latitude weather system interactions and their higher and lower latitude interactions. Seamless Prediction of the Earth System, G. Brunet, S. Jones, and P. Ruti, Eds., WMO-1156, WMO, 77-99.

—, C. M. Dunning, J. Methven, G. Masato, and J. M. Chagnon, 2014: Systematic model forecast error in Rossby wave structure. Geophys. Res. Lett., 41, 2979-2987, doi:10.1002/2014GL059282.

Hamill, T. M., F. Yang, C. Cardinali, and S. J. Majumdar, 2013: Impact of targeted Winter Storm Reconnaissance dropwindsonde data on midlatitude numerical weather predictions. Mon. Wea. Rev., 141, 2058-2065, doi:10.1175/MWR-D-12-00309.1.

Hanesiak, J., and Coauthors, 2010: Storm Studies in the Arctic (STAR). Bull. Amer. Meteor. Soc., 91, 47-68, doi:10.1175/2009BAMS2693.1.

Harnisch, F., M. Weissmann, C. Cardinali, and M. Wirth, 2011: Experimental assimilation of DIAL water vapour observations in the ECMWF global model. Quart. J. Roy. Meteor. Soc., 137, 1532-1546, doi:10.1002/qj.851.

Harr, P. A., and J. M. Dea, 2009: Downstream development associated with the extratropical transition of tropical cyclones over the western North Pacific. Mon. Wea. Rev., 137, 1295-1319, doi:10.1175 /2008MWR2558.1.

$\longrightarrow$, D. Anwender, and S. C. Jones, 2008: Predictability associated with the downstream impacts of the extratropical transition of tropical cyclones: Methodology and a case study of Typhoon Nabi (2005). Mon. Wea. Rev., 136, 3205-3225, doi:10.1175/2008MWR2248.1. Jansa, A., and Coauthors, 2014: MEDEX: A general overview. Nat. Hazards Earth Syst. Sci., 14, 1965-1984, doi:10.5194/nhess-14-1965-2014.

Joly, A., and Coauthors, 1997: The Fronts and Atlantic Storm-Track Experiment (FASTEX): Scientific objectives and experimental design. Bull. Amer. Meteor. Soc., 78, 1917-1940, doi:10.1175/1520 -0477(1997)078<1917:TFAAST>2.0.CO;2.

— of the Fronts and Atlantic Storm-Track Experiment (FASTEX) project. Quart. J. Roy. Meteor. Soc., 125, 3131-3163, doi:10.1002/qj.49712556103.

Jung, T., and M. Leutbecher, 2007: Performance of the ECMWF forecasting system in the Arctic during winter. Quart. J. Roy. Meteor. Soc., 133, 1327-1340, doi:10.1002/qj.99.

Karbou, F., F. Rabier, J.-P. Lafore, J.-L. Redelsperger, and O. Bock, 2010: Global 4D-Var assimilation and forecast experiments using land surface emissivities from AMSU-A and AMSU-B observations. Part II: Impact of adding surface channels on the African monsoon during AMMA. Wea. Forecasting, 25, 20-36, doi:10.1175/2009WAF2222244.1.

Keller, J. H., S. C. Jones, J. L. Evans, and P. A. Harr, 2011: Characteristics of the TIGGE multimodel ensemble prediction system in representing forecast variability associated with extratropical transition. Geophys. Res. Lett., 38, L12802, doi:10.1029/2011GL047275.

,-- , and P. A. Harr, 2014: An eddy kinetic energy view of physical and dynamical processes in distinct forecast scenarios for the extratropical transition of two tropical cyclones. Mon. Wea. Rev., 142, 27512771, doi:10.1175/MWR-D-13-00219.1.

Klocke, D., and M. J. Rodwell, 2014: A comparison of two numerical weather prediction methods for diagnosing fast-physics errors in climate models. Quart. J. Roy. Meteor. Soc., 140, 517-524, doi:10.1002/qj .2172 .

Kristjánsson, J. E., and Coauthors, 2011: The Norwegian IPY-THORPEX: Polar lows and Arctic fronts during the 2008 Andøya campaign. Bull. Amer. Meteor. Soc., 92, 1443-1466, doi:10.1175/2011BAMS2901.1.

Kuhl, D. D., T. E. Rosmond, C. H. Bishop, J. McLay, and N. L. Baker, 2013: Comparison of hybrid ensemble/4DVar and 4DVar within the NAVDAS-AR 
data assimilation framework. Mon. Wea. Rev., 141, 2740-2758, doi:10.1175/MWR-D-12-00182.1.

Lang, S. T. K., S. C. Jones, M. Leutbecher, M. S. Peng, and C. A. Reynolds, 2012: Sensitivity, structure, and dynamics of singular vectors associated with Hurricane Helene (2006). J. Atmos. Sci., 69, 675-694, doi:10.1175/JAS-D-11-048.1.

Langland, R. H., and N. Baker, 2004: Estimation of observation impact using the NRL atmospheric variational data assimilation adjoint system. Tellus, 56A, 189-201, doi:10.1111/j.1600-0870.2004 .00056.x.

— , and Coauthors, 1999: The North Pacific Experiment (NORPEX-98): Targeted observations for improved North American weather forecasts. Bull. Amer. Meteor. Soc., 80, 1363-1384, doi:10.1175/1520-0477(1999)080<1363:TNPENT $>2.0 . \mathrm{CO} ; 2$.

Lazo, J. K., 2012: One economist's entreaty for increased research on weather risk communication. Wea. Climate Soc., 4, 233-235, doi:10.1175/WCAS -D-12-00057.1.

—, M. Lawson, P. H. Larsen, and D. M. Waldman, 2011: U.S. economic sensitivity to weather variability. Bull. Amer. Meteor. Soc., 92, 709-720, doi:10.1175 /2011BAMS2928.1.

Lorenc, A. C., N. E. Bowler, A. M. Clayton, S. R. Pring, and D. Fairbairn, 2015: Comparison of Hybrid4DEnVar and Hybrid-4DVar data assimilation methods for global NWP. Mon. Wea. Rev., 143, 212-229, doi:10.1175/MWR-D-14-00195.1.

Majumdar, S. J., 2016: A review of targeted observations. Bull. Amer. Meteor. Soc., 97, 2287-2303, doi:10.1175 /BAMS-D-14-00259.1.

— for improving numerical weather prediction: An overview. WWRP/THORPEX 15, 37 pp. [Available online at www.wmo.int/pages/prog/arep/wwrp/new /documents/THORPEX_No_15.pdf.]

Martínez-Alvarado, O., L. H. Baker, S. L. Gray, J. Methven, and R. S. Plant, 2014: Distinguishing the cold conveyor belt and sting jet airstreams in an intense extratropical cyclone. Mon. Wea. Rev., 142, 2571-2595, doi:10.1175/MWR-D-13-00348.1.

Matsutani, M., and Coauthors, 2007: Progress in Joint OSSEs: A new nature run and international collboration. 18th Conf. on Numerical Weather Prediction, Salt Lake City, UT, Amer. Meteor. Soc., 12B.5. [Available online at http://ams.confex.com/ams /pdfpapers/124080.pdf.]

Mills, B., and Coauthors, Eds., 2008: SERA North: Economics of Weather, Climate, and Climate Change. Meeting summary, Waterloo, ON, Canada,
Adaptation and Impacts Research Division, Environment Canada, 55 pp.

Moncrieff, M.W., D. E. Waliser, M. J. Miller, M. A. Shapiro, G. R. Asrar, J. Caughey, 2012: Multiscale convective organization and the YOTC virtual field campaign. Bull. Amer. Meteor. Soc., 93, 1171-1187, doi:10.1175/BAMS-D-11-00233.1.

Nordeng, T. E., G. Brunet, and J. Caughey, 2007: Improvement of Weather Forecasts in polar regions. WMO Bull., 56 (4), 250-256.

Powers, J. G., K. W. Manning, D. H. Bromwich, J. J. Cassano, and A. M. Cayette, 2012: A decade of Antarctic science support through AMPS. Bull. Amer. Meteor. Soc., 93, 1699-1712, doi:10.1175/BAMS-D-11-00186.1.

Rabier, F., and Coauthors, 2008: An update on THORPEXrelated research in data assimilation and observing strategies. Nonlinear Processes Geophys., 15, 81-94, doi:10.5194/npg-15-81-2008.

_- and Coauthors, 2010: The Concordiasi project in Antarctica. Bull. Amer. Meteor. Soc., 91, 69-86, doi:10.1175/2009BAMS2764.1.

— Experiment over Antarctica: First results from innovative atmospheric measurements. Bull. Amer. Meteor. Soc., 94, ES17-ES20, doi:10.1175/BAMS-D-12 -00005.1 .

Redelsperger, J.-L., C. D. Thorncroft, A. Diedhiou, T. Lebel, D. J. Parker, and J. Polcher, 2006: African Monsoon Multidisciplinary Analysis: An international research project and field campaign. Bull. Amer. Meteor. Soc., 87, 1739-1746, doi:10.1175/BAMS -87-12-1739.

Renfrew, I. A., and Coauthors, 2008: The Greenland Flow Distortion Experiment. Bull. Amer. Meteor. Soc., 89, 1307-1324, doi:10.1175/2008BAMS2508.1.

Rodwell, M. J., and T. N. Palmer, 2007: Using numerical weather prediction to assess climate models. Quart. J. Roy. Meteor. Soc., 133, 129-146, doi:10.1002/qj.23. Roehrig, R., O. Ndiaye, M. Kamara, E. Afiesimama, A. Diedhiou, A. Diongue-Niang, B. Lamptey, and A. Kamga Foamouhoue, 2008: WWRP/THORPEX African Science Plan: Version 1. WMO/TD-1460, WWRP/THORPEX 10, 37 pp. [Available online at www.wmo.int/pages/prog/a rep/wwrp/new /documents/thorpex_african_science_plan.pdf.]

Rogers, D. P., and Coauthors, 2005: THORPEX international research implementation plan. Version 1, WMO/TD-1258, WWRP/THORPEX 4, 104 pp. [Available online at www.wmo.int/pages /prog/arep/wwrp/new/documents/CD_ROM _implementation_plan_v1.pdf.]

Ruin, I., and Coauthors, 2014: Social and hydrological responses to extreme precipitations: An 
interdisciplinary strategy for postflood investigation. Wea. Climate Soc., 6, 135-153, doi:10.1175/WCAS -D-13-00009.1.

Shapiro, M. A., and A. J. Thorpe, 2004: THORPEX international science plan. Version 3, WMO/ TD-1246, WWRP/THORPEX 2, 55 pp. [Available online at www.wmo.int/pages/prog/arep/wwrp /new/documents/CD_ROM_international_science _plan_v3.pdf.]

— , and Coauthors, 2010: An Earth-system prediction initiative for the twenty-first century. Bull. Amer. Meteor. Soc., 91, 1377-1388, doi:10.1175 /2010BAMS2944.1.

Stensrud, D. J., and Coauthors, 2009: Convectivescale warn-on-forecast system: A vision for 2020 . Bull. Amer. Meteor. Soc., 90, 1487-1499, doi:10.1175 /2009BAMS2795.1.

Swinbank, R., and Coauthors, 2016: The TIGGE project and its achievements. Bull. Amer. Meteor. Soc., 97, 49-67, doi:10.1175/BAMS-D-13-00191.1.

Szunyogh, I., Z. Toth, R. E. Morss, S. J. Majumdar, B. J. Etherton, and C. H. Bishop, 2000: The effect of targeted dropsonde observations during the 1999 Winter Storm Reconnaissance program. Mon. Wea. Rev., 128, 3520-3537, doi:10.1175/1520 -0493(2000)128<3520:TEOTDO >2.0.CO;2.

$\longrightarrow,-$, A. V. Zimin, S. J. Majumdar, and A. Persson, 2002: Propagation of the effect of targeted observations: The 2000 Winter Storm Reconnaissance program. Mon. Wea. Rev., 130, 1144-1165, doi:10.1175/1520 -0493(2002)130<1144:POTEOT>2.0.CO;2.

Thorpe, A. J., 1999: Editorial. Quart. J. Roy. Meteor. Soc., 125, 3129, doi:10.1002/qj.49712556102.

United Nations, 2013: Global assessment report on disaster risk reduction. Accessed 26 May 2016. [Available online at www.preventionweb.net/english /hyogo/gar/2013/en/home/download.html.]

Vaughan, G., and Coauthors, 2015: Cloud banding and winds in intense European cyclones: Results from the DIAMET Project. Bull. Amer. Meteor. Soc., 96, 249-265, doi:10.1175/BAMS-D-13-00238.1.

Waliser, D. E., and M. W. Moncrieff, 2008: Year of Tropical Convection (YOTC): The YOTC Science Plan. WMO/TD-1452, WCRP-130, WWRP/ THORPEX-9, 26 pp. [Available online at www .wmo.int/pages/prog/arep/wwrp/new/documents /YOTC_Science_Plan.pdf.]

— , and Coauthors, 2012: The "year" of tropical convection (May 2008 to April 2010): Climate variability and weather highlights. Bull. Amer. Meteor. Soc., 93, 1189-1218, doi:10.1175/2011BAMS3095.1.

Wang, X., D. Parrish, D. Kleist, and J. S. Whitaker, 2013: GSI 3DVar-based ensemble-variational hybrid data assimilation for NCEP Global Forecast System: Single-resolution experiments. Mon. Wea. Rev., 141, 4098-4117, doi:10.1175/MWR-D-12-00141.1.

Weissmann, M., and C. Cardinali, 2007: Impact of airborne Doppler lidar wind observations on ECMWF forecasts. Quart. J. Roy. Meteor. Soc., 133, 107-116, doi:10.1002/qj.16.

— , and Coauthors, 2011: The influence of assimilating dropsonde data on typhoon track and midlatitude forecasts. Mon. Wea. Rev., 139, 908-920, doi:10.1175/2010MWR3377.1.

Whitaker, J. S., T. M. Hamill, X. Wei, Y. Song, and Z. Toth, 2008: Ensemble data assimilation with the NCEP Global Forecast System. Mon. Wea. Rev., 136, 463-482, doi:10.1175/2007MWR2018.1.

WMO, 2007a: Elements for Life. S. Chacowry, Ed., Tudor Rose, 216 pp.

— 2007b: Madrid conference statement and action plan. WMO Doc., 9 pp. [Available online at www.preventionweb.net/files/2621 _madrid07ActionPlanwebE.pdf.]

Wu, C.-C., and Coauthors, 2009: Intercomparison of targeted observation guidance for tropical cyclones in the northwestern Pacific. Mon. Wea. Rev., 137, 2471-2492, doi:10.1175/2009MWR2762.1. 